HUMOR IN THE ENTREPRENEURIAL PITCH CONTEXT:

THE EFFECT OF HUMOR, INVESTOR REGULATORY FOCUS AND ARGUMENT QUALITY ON PITCH EVALUATIONS AND FUNDING DECISIONS

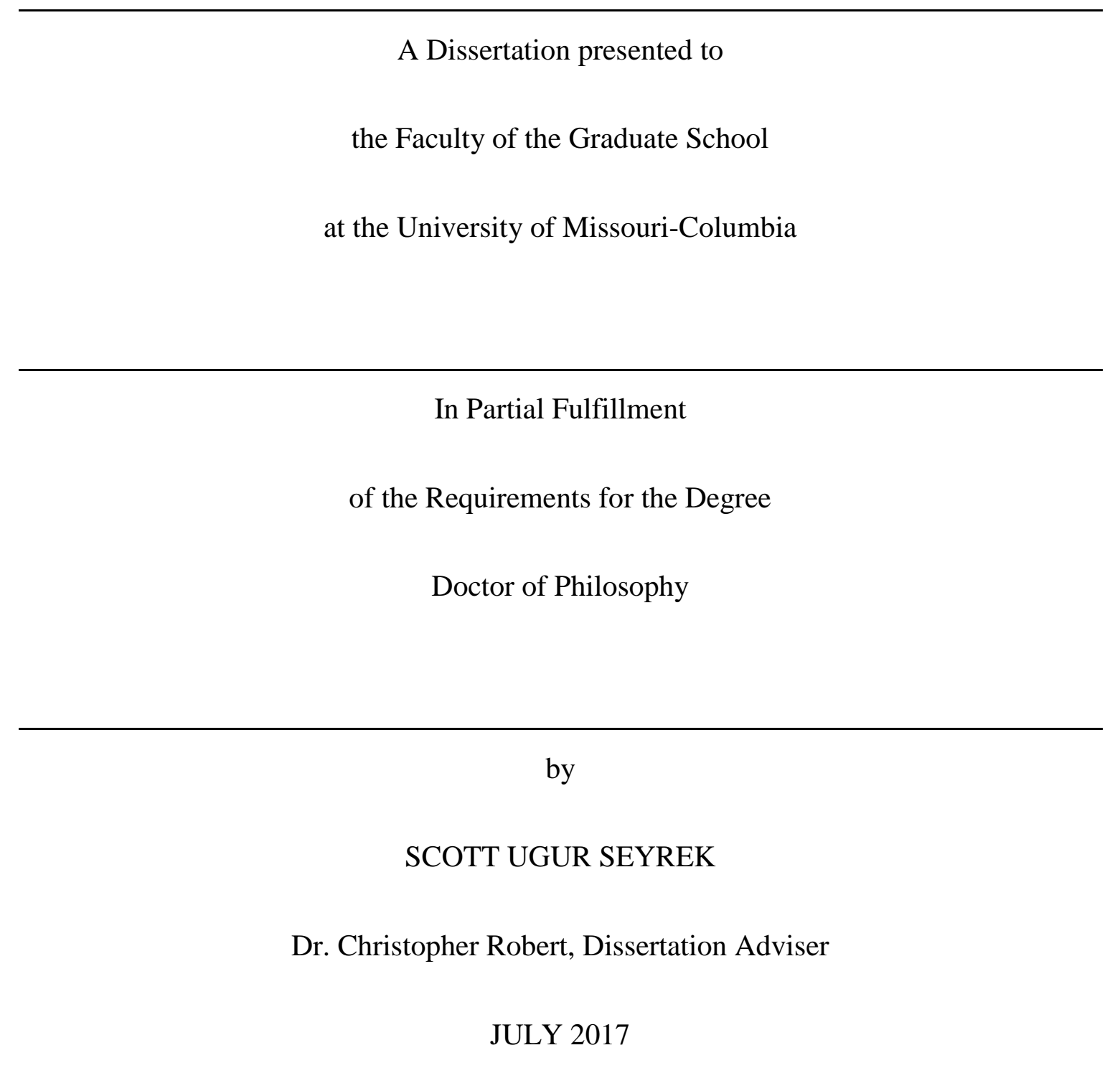


The undersigned, appointed by the dean of the Graduate School, have examined the dissertation entitled:

\section{HUMOR IN THE ENTREPRENEURIAL PITCH CONTEXT: THE EFFECT OF HUMOR, INVESTOR REGULATORY FOCUS AND ARGUMENT QUALITY ON PITCH EVALUATIONS AND FUNDING DECISIONS}

presented by Scott Ugur Seyrek, a candidate for the degree of Doctor of Philosophy, and hereby certify that, in their opinion, it is worthy of acceptance.

Dr. Christopher Robert

Dr. Richard A. Johnson

Dr. Douglas D. Moesel

Dr. Ze Wang 


\section{ACKNOWLEDGEMENTS}

I feel fortunate to have met those at the University of Missouri, the Robert J. Trulaske, Sr. College of Business, and the Management Department who have supported me throughout this experience. I would especially like to thank Professor Christopher Robert, for being the best dissertation adviser one could ever ask for. His guidance, developmental support and patience with me have made this journey enjoyable, and I have gained tremendous knowledge and experience in terms of both scholastic and personal development over the past four years. I am also very grateful to my other dissertation committee members, Professor Douglas Moesel, Professor Richard Johnson and Professor Ze Wang for their support, feedback and guidance. I would also like to thank my best friend who always believed in me, supported me and cheered me up throughout this experience. 


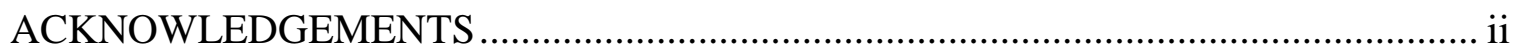

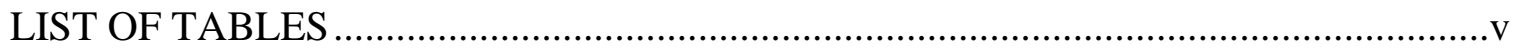

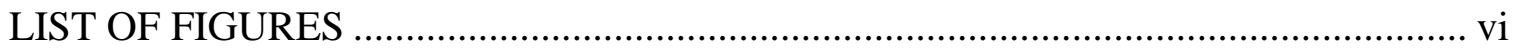

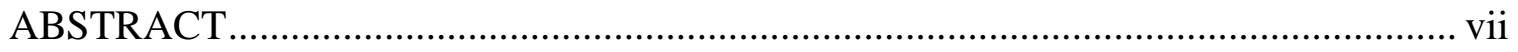

Chapter

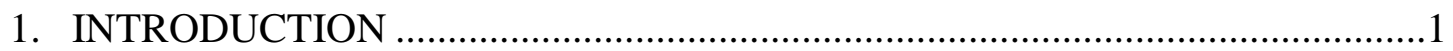

2. LITERATURE REVIEW AND HYPOTHESES DEVELOPMENT........................

Evaluation of Pitch Content

Humor in Entrepreneurship

Affective and Cognitive Processes of Humor

The Hedonic Contingency View and Humor

Investor Motivation and Regulatory Focus

3. METHOD AND ANALYSES

Overview

Instruments

Participants

Procedure

Independent Variables and Manipulations

Dependent Variables

Control and Demographic Variables 
4. RESULTS

Manipulation Checks

Regulatory Focus

Argument Quality

Perceived Humor

Hypothesis Tests

5. DISCUSSION

Theoretical Implications

Practical Implications

Limitations and Future Research

Conclusions

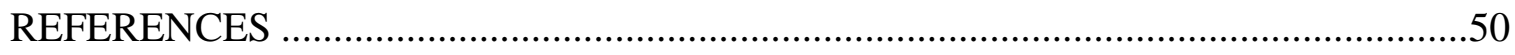

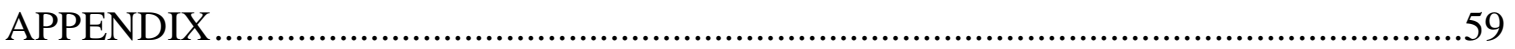

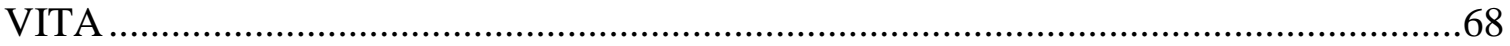




\section{LIST OF TABLES}

Table Page

1. Means, Standard Deviations, Reliabilities, and Correlations .28

2. Two-way ANOVA Descriptive Statistics for Dependent Variables......................32

3. Three-way ANOVA Descriptive Statistics for Dependent Variables....................34

4. Results of Three-way ANOVA for Dependent Variables ....................................35 


\section{LIST OF FIGURES}

Figure

Page

1. Mean Comparisons for Pitch Perceptions ...............................................................33

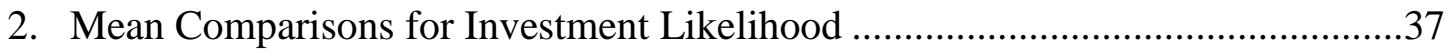




\begin{abstract}
Conventional wisdom and a small body of empirical research suggests that while humor can sometimes be used for negative purposes, it tends to be "good," and associated with positive outcomes. Many entrepreneurs incorporate humor into their entrepreneurial pitches to appeal to investors. But does the common belief about humor's positive effects really hold true for the entrepreneurial pitch context? To examine the role humor plays in entrepreneurial pitches, an experiment was conducted where humor, argument quality and investor regulatory focus were manipulated either before or during a video-recorded entrepreneurial pitch to predict individuals' perceptions of the pitch and their likelihood of investing in the venture. The data consisted of responses by 186 undergraduate students at a large Midwestern university. The results suggested that humor and argument quality interact to influence pitch perceptions and investment likelihood such that humorous content is appreciated when the arguments are strong (i.e., more positive perceptions and higher investment likelihood), whereas the pitches with humor are penalized when the arguments are weak. The results also suggested that this effect was only observed among individuals who were prompted to be promotion-focused during the pitch (i.e., to be open-minded about the pitch and to consider factors beyond economic interests), and not among those who were prevention-focused (i.e., those who were prompted to focus on the venture's risks). The results indicate that although humor might indeed have an impact on investor perceptions, the question of whether entrepreneurs should use humor is more nuanced than the simple "humor is good" conventional wisdom.
\end{abstract}




\section{CHAPTER 1: INTRODUCTION}

One of the main challenges faced by entrepreneurs who seek to form a new venture is securing funds. Historically, entrepreneurs were limited in terms of whom they could turn to for funding unless they had sufficient personal funds to start their ventures. Today, in addition to financial institutions and venture capitalists, sources of resources include individuals who have large sums of money (e.g., angel investors), and the general public (e.g., crowdfunders). Although entrepreneurs today have much more flexibility in their options for where to seek funding, one thing that remains the same is that they need to effectively promote their ideas and convince investors to fund their ventures.

In many cases, entrepreneurs reach out to potential investors to communicate their ideas through a business plan presentation, referred to as "the pitch" (Chen, Yao, \& Kotha, 2009). The pitch can take place in different contexts. For example, a pitch can be delivered in-person, which allows for interaction between the investors and the entrepreneur (e.g., pitching to angel investors). It can also be available online, where the entrepreneur uploads the pitch to an online platform for interested investors to view, and, if interested, fund (e.g., crowdfunding). In any case, every pitch is unique to the entrepreneur who delivers it. The entrepreneur can deliver the pitch in any way he or she pleases, making use of various stylistic strategies to enhance the presentation and increase the persuasiveness of the message.

Humor is one tool that many entrepreneurs use to lighten up the atmosphere, appear friendly, or draw attention to their presentation. For example, in season 6 of the TV show Shark Tank, an entrepreneur named Brian Lim, the founder of CEO of EmazingLights, made a presentation about the latest dance craze, "gloving," which 
involves wearing gloves with lights attached to the tips of fingers. He introduced himself with a giant cartoon headpiece that made the investors chuckle. Eventually, though, he received an investment of $\$ 650,000$ from Mark Cuban and Daymond John (Feloni, 2015).

However, humor's success might depend heavily on the overall pitch context. While some entrepreneurs incorporate humor in a way that results in the pitch being perceived more favorably, other entrepreneurs' use of humor might render the pitch less professional. It is even more problematic that some entrepreneurs may not even be aware that their use of humor actually harms their chances of obtaining much-needed funds. Therefore, although the quality of humor and its ability to amuse or relax investors is certainly an important consideration, this paper will focus on contextual factors that might influence the success or failure of humor during a pitch.

What factors, then, should entrepreneurs take into consideration when incorporating humor into their pitches? In this study, I examine the impact of humor on the evaluation of a pitch and investment likelihood with respect to two contextual factors; argument quality and investors' motivations toward funding a venture. Specifically, I predict that when the arguments are weak, humor will be detrimental to the overall pitch evaluation and investors' likelihood of investment. By the same token, when the arguments are strong, humor will add to the favorability of the pitch evaluation and likelihood of investment. I also predict that evaluation and investment likelihood will depend on investors' regulatory focus during the pitch. Specifically, the impact of humor is expected be more pronounced for promotion-focused investors (i.e., those who have an open-mind when evaluating pitches with motivations that go beyond economic interests) 
than for prevention-focused investors (i.e., those who are motivated to primarily to mitigate financial risk and maximize gains). 


\section{CHAPTER 2: LITERATURE REVIEW}

\section{Evaluation of Pitch Content}

An entrepreneurial pitch is a business plan presentation delivered by an entrepreneur to investors (Chen, Yao, \& Kotha, 2009). During a pitch, as the entrepreneur presents the information about the business idea, investors process this information based on various criteria they consider important. The ultimate goal of the entrepreneur is to make sure that the idea of the venture is clearly and effectively transferred to the recipient, and that the recipient holds favorable perceptions of the pitch and its content. Ideally, investors should feel that the business idea they fund is not only financially promising, but also something they can identify with and is satisfying for the funding they provide (e.g., Ordanini, Miceli, Pizzetti, \& Parasuraman, 2011).

In many cases, making sure the investors clearly understand and identify with the business entails quality arguments. Investors want to be convinced that the ideas they will invest in are worth their time and money. Many studies across disciplines such as marketing, psychology and entrepreneurship have documented that argument quality indeed plays an important role in the evaluation of the message source, and the persuasiveness of the message (e.g., Chaiken, 1980; Gürhan-Canli \& Batra, 2004; Mackie \& Worth, 1989; Petty \& Cacioppo, 1986; Riquelme \& Watson, 2002). Argument quality refers to the strength of arguments supporting the likely success of a venture. Strong arguments are defined as those whose content triggers favorable reactions or elaborations in recipients, which increases the persuasiveness of the message. On the other hand, weak arguments are defined as those whose content triggers unfavorable reactions and elaborations that render persuasion less likely (Moons, Mackie, \& Garcia-Marques, 2009; 
Petty \& Cacioppo, 1986). Argument quality has mostly been researched in persuasion studies where researchers were interested in the interaction between argument quality and variables such as repetition of the message (Moons et al., 2009), positive mood (Mackie \& Worth, 1989; Wegener, Petty, \& Smith, 1995), and positioning and order of message content (e.g., presenting subjects with the heuristic information such as expertise of the source first, and the lengthier and more complex message arguments second) (Kruglanski \& Thompson, 1999).

In the context of this study, argument quality is expected to have a main effect on two pitch outcomes that represent the two dependent variables in this study: pitch perceptions (i.e., the degree to which investors perceive the pitch favorably) and investment likelihood (i.e., the likelihood that investors would invest in the venture if given the opportunity). Given that strong arguments increase and weak arguments decrease the persuasiveness of a message, it is expected that strong arguments will lead to more favorable perceptions of the pitch and increased likelihood of investment, and weak arguments will lead to less favorable perceptions of the pitch and decreased likelihood of investment.

\section{Hypothesis 1a: Pitches with stronger argument quality will be evaluated} more positively than pitches with weaker argument quality.

\section{Hypothesis 1b: Pitches with stronger argument quality will increase investment likelihood relative to pitches with weaker argument quality.}

Importantly, though, humor might influence the way argument quality is perceived. The following section discusses the literature on humor and its role in 
entrepreneurship to better understand how humor can potentially affect investors' reactions to a pitch.

\section{Humor in Entrepreneurship}

The use of humorous appeals has become commonplace in entrepreneurial pitches. Many entrepreneurs inject humor into their pitches, be it through verbal or nonverbal communication, possibly in an attempt to render their presentation delivery more appealing to the audience. Nevertheless, not all attempts at incorporating humor are necessarily successful. Some pitches benefit from the additional "humorous kick," and some look unprofessional. Thus, it is important for entrepreneurs to understand the conditions that are conducive to the successful use of humor.

Despite its ubiquity in everyday human interaction, and its extensive application in pitches, a comprehensive and commonly accepted theoretical umbrella under which humor phenomena can be studied has not yet been developed (Chapman \& Foot, 1977; Lynch, 2002; Robert \& Seyrek, 2017). Martin (2007) suggests that there is still no agreed-upon technical term to explain the feelings elicited by humor other than expressions used by some scholars such as "humor appreciation" (Weisfeld, 1993) or “amusement” (Shiota, Campos, Keltner, \& Hertenstein, 2004). However, in the theoretical domain, there are individual humor theories that are helpful in explaining distinct humor phenomena. For instance, the wheel model of humor (Robert \& Wilbanks, 2012) focuses on the affective qualities of humor and suggests that humor-induced positive-affect results in emotional contagion in group settings, further rendering the environment conducive to humor use and subsequent humor events. Another important framework is the theory of humor elicitation (Wyer \& Collins, 1992), which emphasizes 
humor's cognitive qualities, specifying the conditions under which humor is experienced in different social or nonsocial situations. While each theory might focus on a different aspect of humor, scholars agree that humor can have an important impact on our cognition and emotions (Gervais \& Wilson, 2005; Martin 2007; Mobbs, Hagan, Azim, Menon, \& Reiss, 2003; Robert \& Wilbanks, 2012; Szabo, 2003). In the following section, humor's cognitive and affective components will be discussed to better understand how humor can influence pitch evaluations.

\section{Affective and Cognitive Processes of Humor}

In the small existing literature on humor in organizational contexts, the predominant explanation of humor's effects has been affective (e.g., Cooper, 2008; Robert \& Wilbanks, 2012). For instance, Cooper's (2008) relational process model suggests that humor can stimulate positive affect in different ways, such as through increased perceived similarity and facilitation of self-disclosure between two people. In Robert and Wilbanks' (2012) wheel model of humor, positive affect represents the main driver of humor's effects, which are reinforced through emotional contagion. In addition, studies examining leader-member exchange quality (LMX) suggest that leaders' use of humor influences subordinates' perceptions of leaders, which is reflective of how subordinates feel about their leaders and their personal connections with them (e.g., Gkorezis, Petridou and Xanthiakos, 2014; Pundt and Herrmann, 2015).

Humor's affective qualities in relation to message persuasiveness have also attracted many scholars in the field of marketing. Multiple studies have looked into the role of humor in advertising effectiveness and persuasion, and found that the persuasiveness of humor depends on a number of factors such as the content of the 
commercial and the type of product/service offered. For example, Weinberger and Campbell (1991) found that humor that was related to an advertised product was more effective, especially for low involvement-feeling products (i.e., products that entail a higher level of emotion entering into consideration prior to purchase), and less effective for high-involvement-thinking products. Especially for products whose purchases are based more on emotions (e.g., low involvement-feeling products), humor use in commercials would be more persuasive. This suggests that humor's effects are pronounced in contexts where emotions can influence individuals' behaviors. Pitches bear many similarities to commercials in that in both cases, one party is trying to appeal to another party to convince them of the merits of the business/product being pitched/advertised. In the pitch context then, just like in commercials, humor can elicit positive affect in investors (e.g., Szabo 2003; Houston, McKee, Carroll, \& Marsh, 1998; Mannell \& McMahon, 1982; Martin, Kuiper, Olinger, \& Dance, 1993; Moran, 1995; Newman \& Stone, 1996; White \& Winzelberg, 1992). As I discuss later, affect, in turn, can have important effects on the judgmental process of investors.

Although humor's ability to stimulate positive affect has received considerable attention, other theoretical treatments of humor focus on humor as a cognitive process. Wyer and Collins' (1992) theory of humor elicitation, Apter's (1982) reversal theory, and Koestler's (1964) theory of bisociation all focus on the cognitive process through which humor is elicited. These theories generally fall under the general label of incongruity theory, which asserts that humor is perceived when seemingly incongruous things are presented as being related, and people are amused when they resolve the incongruity and suddenly understand how those thing are related. For example, the incongruity theory 
suggests that a joke works when individuals are presented with incongruous stimuli (e.g., a duck walks into a bar), and then that incongruity is resolved by demonstrating a unique way in which those stimuli are related (e.g., in the punchline). One of the important implications of viewing humor as part of a cognitive process is that doing so illuminates humor's possible connections to other cognitive phenomena. For example, much like humor works by creating and then resolving incongruous elements from different realms of knowledge, the creativity process essentially involves an examination of ideas or concepts that have not previously been linked, and then resolving the disparity between those ideas and concepts by creating a new way of viewing how they might be linked. The parallelism between humor elicitation and creativity has indeed been supported by studies that suggest humor can lead to creativity (Eliav, Miron-Spektor, \& Bear, 2017). For example, in a study by Kudrowitz (2010), individuals who engaged in training in improvisational comedy displayed increased levels of creativity in subsequent tasks. There are also studies that speak to the link between humor and creativity at work suggesting that interacting with a humorous colleague or leader can boost problem solving capabilities (Smith \& Goodschilds, 1963) and improve knowledge sharing (Wood, Beckmann, \& Rossiter, 2011) which enhances creativity (Pan, Sun, \& Chow, 2012). It has been suggested that the link between humor and creativity could be better understood through the concept of cognitive flexibility (Ziv, 1988). Cognitive flexibility refers to an individual's ability to access and integrate distinct knowledge domains, information, and semantic categories (Baas, De Dreu, \& Nijstad, 2008; Eliav et al., 2017). The way cognitive flexibility works is similar to Koestler's (1964) bisociation theory of creativity, which suggests that "bisociative thinking occurs when a problem, 
idea, event or situation is perceived simultaneously in two or more "matrices of thought" or domains" (Dubitzky, Kötter, Schmidt, \& Berthold, 2012, p. 11). In other words, in a creative process, individuals try to make sense of a situation by combining seemingly disparate and distinct units of information and content available in the environment, as well as their own knowledge and experiences. Therefore, humor is expected to work in a similar way, where its impact will depend on the extent to which individuals draw on a relatively wider range of information in the environment to make sense of the situation.

Rather than being two parallel but separate processes, there is indeed building evidence that the cognitive and affective processes involved in humor and creativity are interrelated in important ways. Studies have shown that mood can influence our cognitive processes, playing an important role in creativity and decision-making (e.g., Hirt, Devers, $\&$ McCrea, 2008). Positive affect has been found by many researchers to generate cognitive inclusiveness and flexibility (e.g., Ashby, Isen, \& Turken, 1999; Murray, Sujan, Hirt, \& Sujan, 1990), which has more broadly been referred to as "creativity." For example, in a series of studies conducted by Hirt et al. (2008), participants' activity choices in various tasks were examined under various mood conditions (happy, sad and neutral). The results showed that happy participants exhibited greater cognitive flexibility, and when they were presented with a mood-threatening task, they successfully engaged in creativity to transform the task into a non-threatening one to maintain their positive moods. The results suggest that people in a positive mood tend to be more creative, which supports the link between affect and cognitive processes. 


\section{The Hedonic Contingency View and Humor}

These findings are also in line with the hedonic contingency view of mood and message processing (Wegener \& Petty, 1994; Wegener et al., 1995). Indeed, various studies have suggested that the hedonic contingency view provides an important explanation for the link between affect, cognition and behavior (e.g., Hirt, Devers, \& McCrea, 2008; Wegener \& Petty, 1994; Wegener et al., 1995). The hedonic contingency view suggests that, by nature, individuals desire to achieve positive affect, and in order to do so, they manage their cognitions and behaviors to maintain or improve their positive mood states (Wegener \& Petty, 1994; Wegener et al., 1995). Thus, individuals in a happy mood engage in greater information processing activity as a result of being more attentive to the hedonic consequences of their actions than those in a sad or neutral mood. This is because those in a happy mood want to carefully analyze their situation to avoid actions that can result in a worse mood, and pursue those that can maintain or improve their current mood states. In contrast, for people experiencing negative affect, almost any action will result in a similar or better mood, so it is not as important to carefully analyze situations in order to determine the best course of action. These views were supported in a set of experiments conducted by Wegener and colleagues $(1994,1995)$, where they found that happy people based their decisions about future activities on the affective qualities of these activities to a greater extent than neutral and sad people.

Thus, the literature suggests that humor has both affective and cognitive qualities, and although theories of humor tend to focus on one or the other, there seems to be evidence that humor's affective and cognitive effects are connected. Therefore, it is expected that in a pitch context, the interplay between the affective and cognitive 
qualities of humor will influence investors' reactions to the pitch. The hedonic contingency view provides a good way of conceptualizing how the affective and cognitive processes might be ordered. Specifically, it suggests that affect precedes cognition in that when people are in a positive mood, this increases their scrutiny of the environment and their behavioral choices: we think about what options are most likely to allow us to maintain a positive mood. In contrast, when people are in a neutral or bad mood, scrutiny of the environment and behavioral options is reduced because pretty much any path will maintain the status quo or improve mood. During a pitch where investors pay attention to various stimuli and information pieces surrounding the business idea, positive affect generated by humor can thus increase investors' attentiveness to various pitch components. Given that arguments presented during a pitch are crucial components of the pitch evaluation, it is likely that humor can increase scrutiny on the quality of the arguments presented by the entrepreneur. Therefore, if humor generated by the entrepreneur is accompanied by strong arguments, then investors are expected to have more favorable reactions to the pitch in terms of their perceptions of the pitch and their likelihood of investment. By the same token, if the humor is accompanied by weak and low quality arguments, then investors are expected to have less favorable reactions to the pitch.

Hypothesis 2a: Humor and argument quality will interact such that when accompanied by strong (weak) arguments, humor will positively (negatively) influence pitch perceptions. 
Hypothesis 2b: Humor and argument quality will interact such that when accompanied by strong (weak) arguments, humor will positively (negatively) influence investment likelihood.

I also expect that, in line with the hedonic contingency view, humor's interaction with argument quality will be mediated by positive affect. If positive affect increases scrutiny of argument quality, then humor can influence this scrutiny by generating positive affect. Although it might be challenging to measure the impact of humor on short-term cognitive flexibility, brief and reliable measures of positive affect can be administered in a straightforward way, and so a test for whether affect mediates the impact of humor on pitch evaluations can be conducted. Therefore, I predict a moderated mediation where humor will interact with argument quality to predict pitch perceptions and investment likelihood because humor impacts positive affect.

Hypothesis 3a: Humor's interaction with argument quality in predicting pitch perceptions will be mediated by positive affect (i.e., moderated mediation).

\section{Hypothesis 3b: Humor's interaction with argument quality in predicting} investment likelihood will be mediated by positive affect (i.e., moderated mediation).

\section{Investor Motivation and Regulatory Focus}

So far the discussion has focused on humor, affect and argument quality as important components that can influence pitch evaluations, but these components are predominantly driven by the entrepreneur's actions during the pitch (e.g., their use of humor and their preparedness). For example, it is at the discretion of the entrepreneur to decide whether to incorporate humor, which can potentially lead to positive affect. 
Similarly, argument quality depends on how marketable the entrepreneur can make the pitch based on the information about the venture's current situation and potential.

However, to better understand the dynamics involved in the pitch evaluation process, it is important to examine investor characteristics to help understand when humor will lead to more or less focus by investors on humor and argument quality.

An important characteristic of investors that can play a significant role in pitch evaluation is their motivation to fund a venture. Investors may be motivated to view and interpret entrepreneurial pitches in different ways due to their different desires and goals, and their motivations might impact their ability or willingness to examine various components of entrepreneurial pitches. Studies indeed suggest that investors' motivations toward funding can vary significantly. For example, some investors focus mostly on economic gains, and they aim to minimize financial risk and maximize return-oninvestment (e.g., Van Osnabrugge \& Robinson, 2000). Other investors focus on the opportunity to make an interesting idea possible through financial support, a sense of "social participation" in helping someone, a strong sense of identification with the project or the entrepreneur and satisfaction from providing a donation: reasons that go beyond economic interests (see review by Ordanini et al., 2011). Thus, an important implication of these differences in investment motivations is that they can heavily influence the pitch evaluation outcomes by guiding investors' attitudes toward pitch components and their behavior throughout the pitch evaluation process.

To better understand the role of investor motivation in pitch evaluation, and this distinction between minimizing risk on one hand, and a focus on social participation, or identification with the venture idea on the other, I draw on regulatory focus theory 
(Higgins, 1997, 1998) to help explain how humor and investor motivation might interact with humor and argument quality to influence perceptions of the pitch and funding decisions. Regulatory focus theory is a self-regulation and goal attainment theory, and suggests that people engage in self-regulation to bring themselves into alignment with their standards and goals through two self-regulatory foci: promotion and prevention (Brockner, Higgins \& Low, 2004). When promotion-focused, people are influenced by the presence and absence of positive stimuli (Gamache, McNamara, Mannor, \& Johnson, 2015). They strive for growth and accomplishment through ideals, hopes and aspirations by using eagerness strategies (e.g., reading extra material for class) (Crowe \& Higgins, 1997). When prevention-focused, people are influenced by the presence and absence of negative stimuli. They strive for security and protection through pursuing obligations and duties by engaging is vigilance strategies (e.g., avoiding distractions while studying). Thus, in the case of promotion-focus, potential gains are salient to individuals and they try to engage in actions sooner whenever they see an opportunity to maximize gains and minimize non-gains. In the case of prevention-focus, they try to avoid potential losses and thus engage in mandatory actions to minimize losses and maximize non-losses.

Regulatory focus is contingent on various "situational and dispositional factors" (Brockner \& Higgins, 2001: 40) as well as the immediate environment (Förster, Higgins \& Idson, 1998; Higgins, 2000). For example, some people may be more prevention- or promotion-focused regardless of context. By the same token, there may be certain environmental conditions that support a prevention- or a promotion-focus in most individuals. The interactions between these contingency factors can lead to the formation of distinct regulatory foci in individuals. For example, for a normally promotion-focused 
worker whose goal is to voice concerns to the management to improve working conditions, a strictly hierarchical corporate culture might induce an increase in prevention-focus. However, when individuals' goal attainment strategies are in line with the immediate circumstances, then the effects of promotion and prevention foci are magnified (Gamache et al., 2015), a situation known as regulatory fit (Higgins, 2000). Regulatory fit generates feelings of rightness. The main assumption underlying the use of this theory to explain investor behavior is that for any individual, experiencing regulatory fit is desirable, and thus an individual would lean toward engaging in actions and strategies that would create a fit for their individual goals. This inclination to create the fit between goals and the strategies to attain them can help explain investor behavior.

In a pitch context, regulatory fit might suggest that investors display attitudes or engage in actions that are in line with their investment motivations, and these motivations can influence the extent to which they will be affected by humor or other aspects of an entrepreneurial pitch. For example, investors who are focused on financial gains and avoidance of risk might display avoidant behavior, because they need to be careful about their decisions. Such behaviors are in line with those displayed by prevention-focused individuals. A prevention-focus in investors will likely cause them to have a narrower view of the pitch, such that they attend primarily to a limited set of cues that might signal whether the venture is risky. Such a narrow focus might block the effects of humor or other pitch content that is not directly relevant to examining risk. In other words, their emphasis on risk avoidance can keep them from attending to a larger amount of stimuli, curbing their appreciation of the pitch for its creativity, style of delivery and use of humor. In this case, humor may not be as impactful on prevention-focused investors, and 
the entrepreneur may fail to elicit the desired evaluations for the business pitch through the use of humor. On the other hand, other investors might have motives that go beyond immediate financial considerations, leading to a more comprehensive view of the pitch. They are more likely to focus on a wider range of pitch characteristics, and to how they feel about the venture (e.g., contributing to something they can identify with or something that gets them excited about the idea). These characteristics are in line with a promotionfocus. A promotion-focus in investors will cause them to pay attention to a larger amount of information and stimuli during the pitch such as the pitch delivery style, creativity, and use of humor, making them much more open to the effects of humor.

Investors' regulatory focus and how it guides their attentiveness to pitch components will thus influence the way they process argument quality and humor. It has been hypothesized earlier in the paper that humor and argument quality will interact such that humor will strengthen pitch evaluation and investment likelihood when accompanied by strong arguments, and will weaken them when the arguments are weak. In the context of regulatory focus, I expect that because people with a prevention focus will be less attentive to humor, humor use by the entrepreneur will not impact the degree to which they scrutinize argument quality. By the same token, for people with a promotion focus, their relatively higher cognitive flexibility and openness to humor will cause them to increase their scrutiny of argument quality. Therefore, I expect the pattern proposed in the two-way interaction between argument quality and humor to be observed more strongly when investors have a promotion-focus than a prevention-focus. 
Hypothesis 4a: The interaction between humor and argument quality on pitch perceptions (i.e., that humor will lead to positive (negative) pitch perceptions when accompanied by strong (weak) arguments) will be observed for promotionfocused investors more strongly than for prevention-focused investors.

Hypothesis 4b: The interaction between humor and argument quality on investment likelihood (i.e., that humor will lead to higher (lower) investment likelihood when accompanied by strong (weak) arguments) will be observed for promotion-focused investors more strongly than for prevention-focused investors. 


\section{CHAPTER 3: METHOD AND ANALYSES}

\section{Overview}

This study employed a 2x2x2 experimental design where participants viewed an entrepreneurial pitch that was recorded with the help of an actress. Participants in this study were asked to view a video recording of an entrepreneurial pitch and a) provide an overall evaluation of the pitch, and b) indicate their likelihood of investment in the venture (the two dependent variables for the study). There were 4 versions of the video pitch, which varied based on humor (i.e., whether the pitch content had humorous or nonhumorous/neutral appeals) and argument quality (i.e., whether the pitch content featured weak arguments or strong arguments about the potential success and/or quality of development of the business idea). Participants were randomly shown one of the 4 versions. The instructions prior to viewing the video also manipulated regulatory focus

(i.e., prevention and promotion focus), and participants were randomly assigned to one of the two conditions. After viewing the pitch, participants were asked to complete a questionnaire that measured their perceptions of the pitch and their likelihood of investment.

\section{Instruments}

The entrepreneurial pitch was recorded with the help of an actress who performed as the entrepreneur/founder of the business. The pitch concept was about a consultancy service that helps students get a job when they graduate from college. Different versions of the pitch were scripted and recorded such that argument quality (high vs. low) and humor (high vs. low humor/neutral content) systematically varied between the four 
versions. Portions of the videos addressing argument quality and using humor (or not) did not overlap.

After the initial videos were recorded, pilot tests were conducted using Amazon Mechanical Turk users to get feedback about the videos and specific manipulations. The feedback from the results was used to re-record portions of the video pitches to improve the strength of the manipulations. In particular, pilot participants rated various samples of humorous material (e.g., video clips, photos) that were chosen for subsequent inclusion in the final versions of the videos. In addition, because the distinction between strong and weak argument versions was statistically significant but somewhat weak in the pilot videos, the argument portions of video scripts were re-written and re-recorded to strengthen the distinction between strong and weak arguments. With the new versions of the scripts, a pilot study was conducted using Mechanical Turk to check for the argument quality manipulation where respondents randomly received the script with either weak or strong arguments, and were asked to evaluate the argument quality in the script. The results of the pilot test conducted with 34 participants on Amazon Mechanical Turk that focused only on the ratings of the scripts with regard to argument quality (i.e., without humor and without regulatory focus) confirmed a difference in ratings of argument quality, where the mean argument quality score for the weak arguments was significantly lower than that for the strong arguments $[d=.97,95 \% \mathrm{CI},-1.63$ to $-0.32, t(32)=-3.04, p$ $<.05]$

After splicing in strong/weak argument segments, and humorous/non-humorous segments, all videos were comparable in length, at about 4.5 minutes. 


\section{Participants}

Undergraduate students at a large Midwestern university $(\mathrm{N}=271)$ volunteered to participate in exchange for course credit. Participants completed the study at a terminal in a computer lab, where the instruction version (i.e., prevention or promotion focus) and video version (i.e., high/low argument quality and humorous/non-humorous) were randomly assigned. Participants used headphones to listen to the videos they were assigned.

\section{Procedure}

\section{Independent variables and manipulations}

Prevention and promotion focus were manipulated in the instructions that were provided prior to watching the video. Specifically, participants were instructed to go into the video with a particular mindset (i.e., promotion or prevention). The instructions used for this purpose were based on the suggestions of Halvorson and Higgins (2013) for inducing promotion and prevention focus. In order to induce prevention focus, the instructions were framed in terms of "losses," whereas to induce promotion-focus, the instructions were framed with a focus on "gains" (177). These instructions were created using some of the language of the items in the Work Regulatory Focus Scale by Neubert, Kacmar, Carlson, Chonko and Roberts (2008) (see Appendix A for these statements). At the end of the study, to make sure the manipulation influenced participants' preventionor promotion-focused mindset, they were asked to pick one option as shown below, where the language in these two options was based on the two versions of the instructions participants were given prior to watching the video: 
Which of the following statements best reflects your approach when evaluating the pitch and responding to questions in this experiment?

"I am careful to avoid risks and avoid exposing myself to potential financial loss"

"I am comfortable taking risks if it means personal growth or giving entrepreneurs a chance to grow"

Argument quality was manipulated such that one version systematically featured weak arguments, whereas the other featured strong arguments. Weak arguments were designed to indicate that the business idea was not particularly well-thought-out, did not include experienced or a highly professional staff, and that there was little evidence of success of the venture so far. For example, weak arguments included statements such as "our service was recently developed by a group of inexperienced undergraduate students," "we are excited to be launching this business for the first time," and "we will have you complete a basic, generic questionnaire." In contrast, strong arguments were made in parallel to the weak arguments, and were meant to convey that the business venture had good initial success, and was being run by appropriate professional staff. For example, strong arguments included statements such as "our service is developed by professional career consultants with a combined 100 years of recruiting experience," "In the past two years, we [...] had the opportunity to serve approximately 200 students who we have helped get a position with a nationally recognized preferred employer," and "we will have you complete our proprietary professionally-designed computerized personality profile." This manipulation was tested using a semantic differential scale consisting of 
four pairs of bipolar adjectives (weak-strong, unpersuasive-persuasive, not convincingconvincing, bad argument-good argument) (Zhang, 1996) (Cronbach's alpha = .91).

Humor was manipulated such that the humorous appeals included in the videos (e.g., video clips, photos) were chosen based on the results of the pilot study described previously, in which respondents rated various video clips and photos in terms of how humorous they perceived them to be. Video clips and photos that were deemed to be the most humorous were added to the humorous versions of the pitch (e.g., a frustrated worker throwing his keyboard), whereas the nonhumorous versions featured a clip or a photo that was neutral in tone (e.g., a workplace setting showing normal everyday interactions among employees). There were 5 places throughout the videos where neutral or humorous clips/photos were used. A manipulation check for perceived humor was conducted using 9 items, 3 of which were based on the humor scale from Zhang (1996) that uses bipolar adjectives (not humorous-humorous, not funny-funny, not amusingamusing). All items were in the statement format such as "The entrepreneur tried to incorporate humor into the pitch," "I thought the pitch was amusing," "I appreciated the pitch for its light-hearted content," "The humor was integrated effectively," and "I thought the pitch was humorous" (Cronbach's alpha $=.95)$.

In addition, to explore the effect of humor on affect, positive affect was measured using the Pleasant Activated scale items developed by Barrett and Russel (1998). After participants have viewed the pitch, they were first asked to complete this scale by rating 8 items on a 5-point Likert Scale $(1=$ very slightly or not at all, $2=$ a little, $3=$ moderately, 4 = quite a bit, 5 =extremely): "I feel interested in what I am doing at the moment," "I feel pretty enthusiastic about my life right now," "I'm feeling inspired," "Right now, life 
feels terrific," "I'm feeling energetic and positive," "I feel determined," "I feel very focused and on task," "I'm feeling lively and cheerful." (Cronbach's alpha $=.89$ ).

\section{Dependent Variables}

Pitch perceptions were measured with a four-item scale adapted from Zhang (1996). This scale has been used in marketing studies to measure attitudes toward ads. Given that ads and pitches share a similar underlying persuasion process, this measure was deemed appropriate for this study. The items came after the following statement: "The business pitch was...." The response scale used a 5-point semantic differential scale (unpleasant-pleasant, unlikeable-likeable, not irritating-irritating, not interestinginteresting) (Cronbach's alpha $=.87)$.

Investment likelihood was measured with a three item scale based on Zhang (1996). Participants were asked "How likely are you to fund this pitch?", "What is the probability that you would fund this pitch?", and "To what extent is it possible for you to fund this pitch?" Responses were made on a 5-point Likert scale with parallel anchors (i.e., unlikely-likely, improbable-probable, and impossible-possible) $($ Cronbach's alpha $=$ $.92)$.

\section{Control/Demographic Variables}

The control variables included prior investment experience (number of investments), gender, age, current level of education, major in college, GPA, and participants' ability to understand English. Participants answered these questions at the end of the survey. The questions were coded as follows: investment experience $(0=$ " 0 ", $1=$ " $1-3$ times", $2=$ "more than 3 "), gender $(0=$ male, $1=$ female, $2=$ prefer not to 
answer), current level of education in progress $(0=$ other, $1=$ bachelor's degree, $2=$

master's degree, $3=$ doctorate degree $)$, major ( $0=$ business, $1=$ non-business $)$, and ability to understand English $(0=$ very well, $1=$ well, $2=$ not well $)$. 


\section{CHAPTER 4: RESULTS}

\section{Manipulation checks}

Regulatory focus. The results of the manipulation check for regulatory focus showed that only 186 of the 271 participants passed this manipulation check. Specifically, they were asked whether they viewed the pitch in compliance with the regulatory focus instructions (i.e., prevention or promotion) they were presented at the beginning of the study. As a result, the reduced set $(N=186)$ of participants that passed the manipulation check was used for all subsequent analyses. However, a robustness analysis was done comparing the results of the reduced set (i.e., those who passed the manipulation check) to the full set of participants. This analysis demonstrated that the full and reduced samples showed very similar patterns of results. Most notably, the significant three-way interaction to be discussed later in this section was obtained for both the full and reduced samples.

Argument quality. An independent samples t-test was conducted to assess the manipulation of argument quality. There were 90 participants in the weak argument condition, and 96 in the strong argument condition. The mean argument quality score was lower for the weak argument condition $(M=2.76, S D=1.08)$ than the strong argument condition $(M=2.99, S D=.97)$. Although, the mean difference of -0.23 [95\% CI, -0.52 to $0.07, t(184)=-1.52, \mathrm{p}=.13$ ] was not statistically significant, it is possible that perceptions of argument quality were influenced by interactions with other independent variables (i.e., perceived humor and regulatory focus), and not simply judged independently of other information provided by the instructions or in the videos. 
Perceived humor. An independent samples t-test was conducted to check the humor manipulation. There were 82 responses for the nonhumorous condition, and 104 responses for humorous condition. Consistent with expectations, the mean humor score was significantly lower for the nonhumorous condition $(M=1.98, S D=.65)$ than the humorous condition $(M=3.00, S D=.91$, [95\% CI for the mean difference was -1.24 to $0.79), t(184)=-8.54, p<.05]$.

\section{Hypothesis Tests}

Table 1 reports the correlations, means, standard deviations, and scale reliabilities for all study variables. 

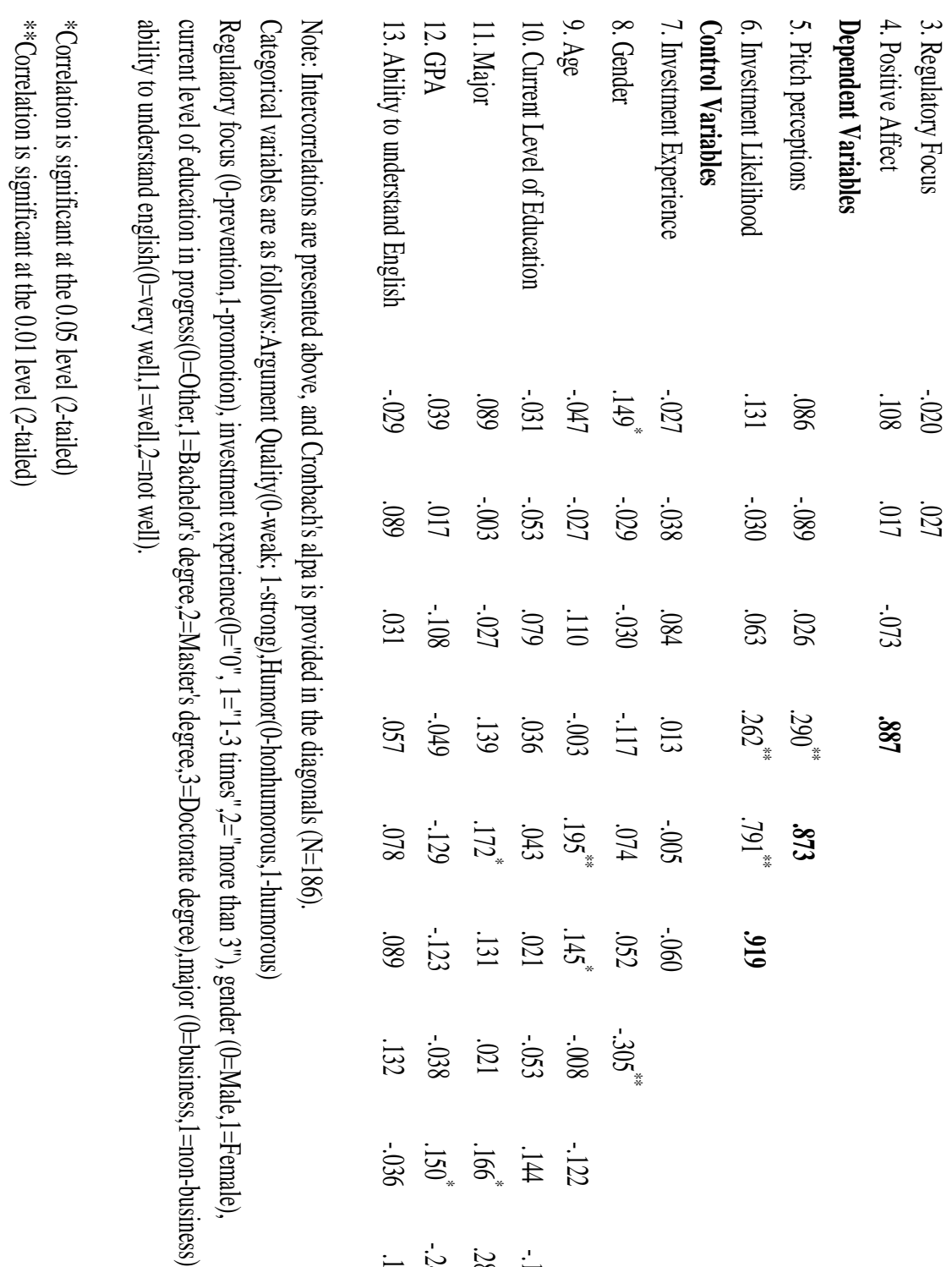

僖旁

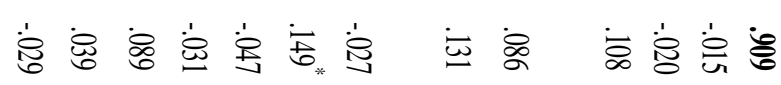

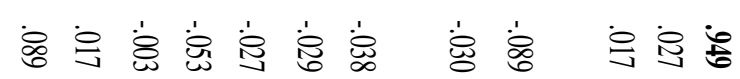

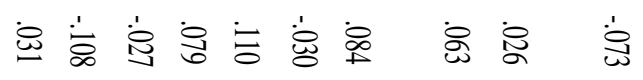

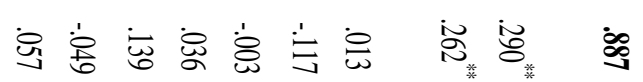

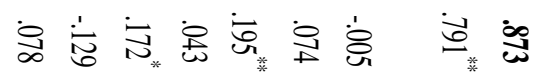

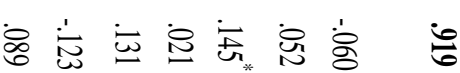

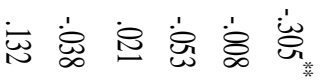

灾荾客宝离

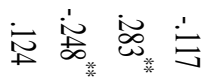

它 总

家

铵

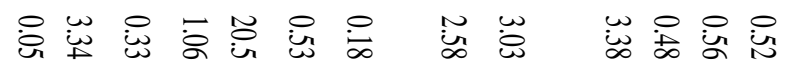

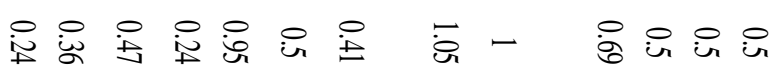

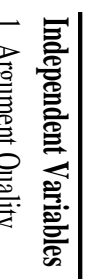

衰 
Although the randomized control design should make groups probabilistically equivalent across variables that might impact dependent variables, regression analyses were conducted to examine whether the control variables, including prior investment experience (number of investments), gender, age, current level of education, major in college, GPA, and participants' ability to understand English, had a significant impact on the results. These analyses suggested that only age had a significant (positive) effect on investment likelihood, and the patterns of results for hypotheses tests did not differ based on including or excluding age in the analyses. Therefore, all hypotheses tests reported below were conducted using ANOVA without covariates, and are described based on relevant mean differences between conditions.

Hypothesis 1a suggested that argument quality would be related to pitch perceptions such that pitches with strong arguments would be rated more positively than those with weak arguments. Results of a one-way ANOVA showed that the mean for pitch perceptions for the high argument quality condition $(M=3.12, S D=.99)$ was not significantly greater than the mean for the low argument quality condition $[M=2.95, S D$ $=1.00 ; F(1,184)=1.36$, n.s., $\eta_{p}^{2}=.01$, power $\left.=.21\right]$. Similarly, hypothesis $1 \mathrm{~b}$ suggested that argument quality would be related to investment likelihood such that participants would be more likely to invest in venture ideas when pitches had strong rather than weak arguments. One-way ANOVA results showed that the mean for investment likelihood for the high argument quality condition $(M=2.71, S D=1.10)$ was not significantly greater than the mean for the low argument quality condition $[M=2.44, S D=.97 ; F(1,184)=$ 3.23 , n.s., $\eta_{p}^{2}=.02$, power $\left.=.43\right]$. Importantly, even though the results show that hypotheses $1 \mathrm{a}$ and $1 \mathrm{~b}$ were not supported, this result is qualified by the 3-way interaction 
between argument quality, humor, and regulatory focus, which will be discussed later in this section.

Hypothesis 2a suggested that humor and argument quality would interact such that when accompanied by strong (weak) arguments, humor would positively (negatively) influence pitch perceptions. ANOVA indicated that the humor $\mathrm{x}$ argument quality interaction was significant, $F(1,182)=4.34, p<.05, \eta_{p}^{2}=.02$, power $=.55$. Mean pitch perceptions for nonhumorous and humorous pitches were $3.22(S D=1.13)$ and $2.74(S D=.85)$, respectively in the weak argument condition; and $3.05(S D=.92)$ and $3.17(S D=1.04)$, respectively, in the strong argument condition. Pairwise comparisons revealed a statistically significant mean difference in pitch perceptions between the weak argument/humorous condition and strong argument/humorous condition $[d=.44 ; 95 \% \mathrm{CI}, .05$ to $.82, F(1,182)=5.06, p<.05]$, and a significant mean difference between the weak argument/humorous condition and weak argument/nonhumorous condition $[d=.49 ; 95 \% \mathrm{CI}, .08$ to $.90, F(1,182)=5.45, p<.05]$. This pattern of results is consistent with the hypothesis, and suggests that while humor appeared to augment perceptions of pitches that have strong arguments, it weakened pitch perceptions when paired with weaker arguments.

Hypothesis $2 \mathrm{~b}$ was parallel to Hypothesis 2a, but used investment likelihood as the dependent variable. ANOVA indicated that the humor $\mathrm{x}$ argument quality interaction was significant for investment likelihood, $F(1,182)=5.23, p<.05, \eta_{p}^{2}=.03$, power $=$ .62. Mean investment likelihood for nonhumorous and humorous pitches was $2.68(S D=$ 1.07) and $2.25(S D=.86)$, respectively, in the weak argument condition; and $2.56(S D=$ 
$1.05)$ and $2.84(S D=1.14)$, respectively, in the strong argument condition. Pairwise comparisons revealed a statistically significant mean difference in investment likelihood between the weak argument/humorous condition and strong argument/humorous condition $[d=.58 ; 95 \% \mathrm{CI}, .18$ to $.98, F(1,182)=8.23, p<.05]$. The mean difference between the weak argument/nonhumorous condition and weak argument/humorous condition approached but did not reach significance $[d=.42 ; 95 \%$ CI, -.01 to $.85, F$ $(1,182)=3.66, p<.10]$. This pattern of results is consistent with the hypothesis and suggests that humor appeared to increase investors' likelihood of funding pitches that have strong arguments, and decreases their likelihood for pitches that have weak arguments. As with Hypotheses 1a and 1b, a significant three-way interaction (Hypotheses 4a and 4b) qualifies the significant two-way interactions reported for Hypotheses $2 \mathrm{a}$ and $2 \mathrm{~b}$, and those results are discussed below.

Hypothesis $3 a$ and $3 b$ suggested that the effect of humor on pitch perceptions and investment likelihood would be mediated by positive affect. However, because humor was not correlated with positive affect $(r=.02$, n.s.), further examination of this hypothesis was precluded, and both Hypothesis $3 \mathrm{a}$ and $3 \mathrm{~b}$ were rejected. 
Table 2

Two-way ANOVA Descriptive Statistics for Pitch perceptions and Investment Likelihood

\begin{tabular}{|c|c|c|c|c|c|}
\hline \multirow[t]{7}{*}{ Pitch perceptions } & \multicolumn{2}{|l|}{ Variable } & Mean & SD & $\mathbf{n}$ \\
\hline & \multicolumn{5}{|c|}{ Nonhumorous } \\
\hline & & Weak arguments & 3.22 & 1.13 & 39 \\
\hline & & Strong arguments & 3.05 & .92 & 43 \\
\hline & \multicolumn{5}{|c|}{ Humorous } \\
\hline & & Weak arguments & 2.74 & .85 & 51 \\
\hline & & Strong arguments & 3.17 & 1.04 & 53 \\
\hline \multirow[t]{7}{*}{ Investment Likelihood } & Variable & & Mean & SD & $\mathbf{n}$ \\
\hline & Nonhumo & ous & & & \\
\hline & & Weak arguments & 2.68 & 1.07 & 39 \\
\hline & & Strong arguments & 2.56 & 1.05 & 43 \\
\hline & Humorou & & & & \\
\hline & & Weak arguments & 2.25 & .86 & 51 \\
\hline & & Strong arguments & 2.84 & 1.14 & 53 \\
\hline
\end{tabular}

Hypothesis $4 \mathrm{a}$ and $4 \mathrm{~b}$ suggested a 3-way interaction such that regulatory focus, humor and argument quality would interact to predict pitch perceptions and investment likelihood. Specifically, hypothesis 4a suggested that investors exposed to humor that accompanies strong (weak) arguments would perceive pitches positively (negatively), especially when they have a promotion focus. ANOVA indicated that the 3-way interaction was significant $\left(\eta_{p}^{2}=.04\right.$, power $\left.=.8\right)($ see Table 3$)$. Means with $95 \%$ CI bars are presented in Figure 1. A visual inspection of the pattern of means in Figure 1 suggested that the interaction between argument quality and humor (as predicted in Hypotheses $2 \mathrm{a}$ and $2 \mathrm{~b}$ ) was only present in the promotion-focused condition, and not the prevention-focused condition. Pairwise comparisons of means confirmed this basic 
pattern. Specifically, for promotion-focused investors, there was a statistically significant mean difference between weak and strong arguments in the nonhumorous condition $(d=$ $.67,95 \%$ CI, .05 to $1.29, p<.05$ ), and a statistically significant mean difference (in the opposite direction) between strong and weak arguments in the humorous condition $(d=$ $.78,95 \% \mathrm{CI}, .24$ to $1.32, p<.05)$. For promotion-focused investors presented with weak arguments, there was also a significant mean difference between the humorous and nonhumumorous condition $(d=1.05 ; 95 \% \mathrm{CI},-1.63$ to-.47, $p<.05)$. Such significant differences were not observed in the strong argument condition, or for preventionfocused investors in any of the conditions. The results suggest that the basic pattern observed in the two-way interaction between humor and argument quality is driven by the fact that those differences were observed in the promotion-focused condition, but not the prevention-focused condition.

\section{Figure 1}

Mean comparisons for pitch perceptions
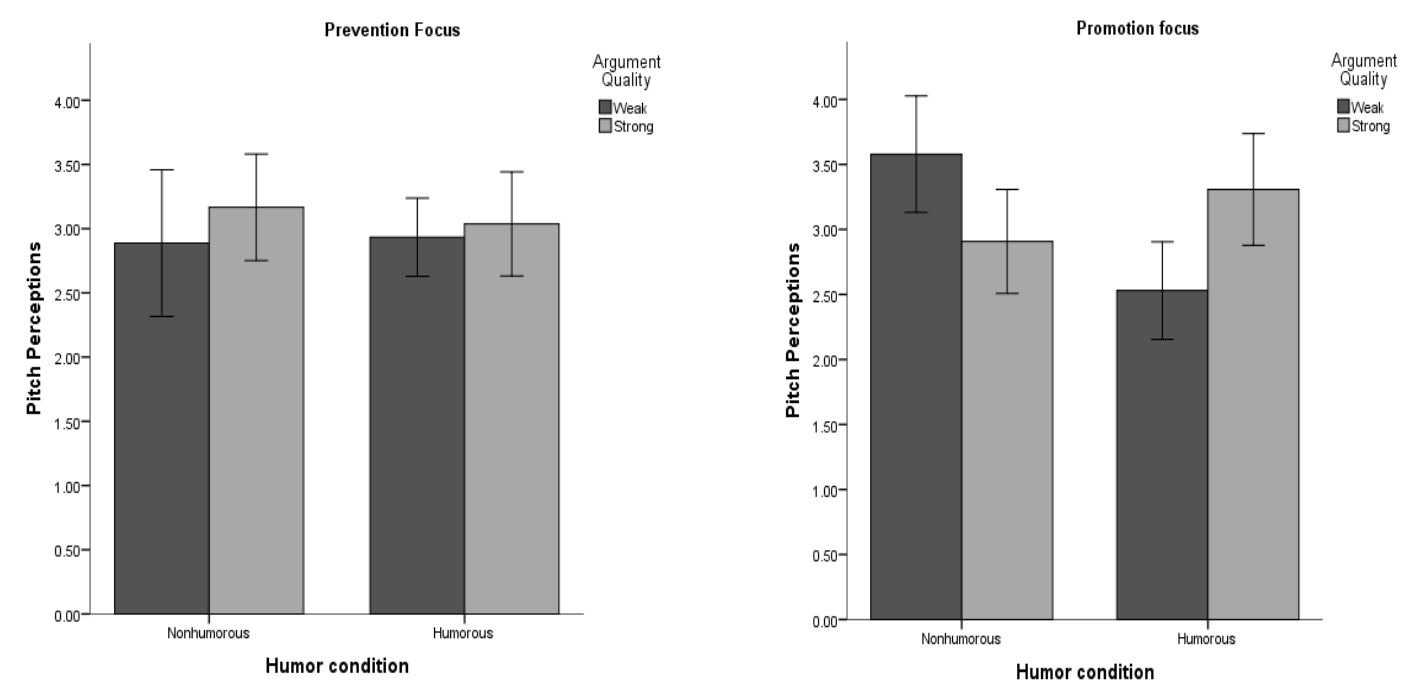
Table 3

Three-way ANOVA Descriptive Statistics for Pitch perceptions and Investment Likelihood

\begin{tabular}{|c|c|c|c|c|}
\hline \multirow[t]{15}{*}{ Pitch perceptions } & Variable & Mean & SD & $\mathbf{n}$ \\
\hline & Prevention & & & \\
\hline & Nonhumorous & & & \\
\hline & Weak arguments & 2.89 & 1.22 & 20 \\
\hline & Strong arguments & 3.17 & .98 & 24 \\
\hline & Humorous & & & \\
\hline & Weak arguments & 2.93 & .75 & 26 \\
\hline & Strong arguments & 3.04 & 1.03 & 27 \\
\hline & Promotion & & & \\
\hline & Nonhumorous & & & \\
\hline & Weak arguments & 3.58 & .93 & 19 \\
\hline & Strong arguments & 2.91 & .83 & 19 \\
\hline & Humorous & & & \\
\hline & Weak arguments & 2.53 & .91 & 25 \\
\hline & Strong arguments & 3.31 & 1.06 & 26 \\
\hline \multirow[t]{15}{*}{ Investment Likelihood } & Variable & Mean & SD & $\mathrm{n}$ \\
\hline & Prevention & & & \\
\hline & Nonhumorous & & & \\
\hline & Weak arguments & 2.25 & .87 & 20 \\
\hline & Strong arguments & 2.54 & 1.08 & 24 \\
\hline & Humorous & & & \\
\hline & Weak arguments & 2.51 & .76 & 26 \\
\hline & Strong arguments & 2.69 & 1.18 & 27 \\
\hline & Promotion & & & \\
\hline & Nonhumorous & & & \\
\hline & Weak arguments & 3.12 & 1.10 & 19 \\
\hline & Strong arguments & 2.58 & 1.04 & 19 \\
\hline & Humorous & & & \\
\hline & Weak arguments & 1.99 & .89 & 25 \\
\hline & Strong arguments & 2.99 & 1.10 & 26 \\
\hline
\end{tabular}




\section{Table 4}

Three-way ANOVA Results for Pitch perceptions and Investment Likelihood

\begin{tabular}{llcccc}
\hline Pitch perceptions & & & & & \\
\hline & Source & SS & df & MS & F \\
\cline { 2 - 6 } & Argument quality & 0.69 & 1 & 0.69 & 0.73 \\
& Humor & 1.53 & 1 & 1.53 & 1.63 \\
& Regulatory focus & 0.26 & 1 & 0.26 & 0.27 \\
& Argument quality x Humor & 4.63 & 1 & 4.63 & $4.9^{*}$ \\
& Argument quality x Regulatory & & & & \\
& focus & 0.22 & 1 & 0.22 & 0.23 \\
& Humor x Regulatory focus & 0.91 & 1 & 0.91 & 0.96 \\
& Argument quality x Humor x & & & & \\
& Regulatory focus & 7.51 & 1 & 7.51 & $7.96^{*}$ \\
& Error & 168.04 & 178 & 0.94 & \\
\hline
\end{tabular}

Note: $\mathrm{N}=186, \mathrm{R}^{2}=.08$, adj. $\mathrm{R}^{2}=.05,{ }^{*} \mathrm{p}<.05$

\begin{tabular}{llcccc}
\hline $\begin{array}{l}\text { Investment } \\
\text { Likelihood }\end{array}$ & & & & & \\
\hline & Source & SS & df & MS & F \\
\cline { 2 - 7 } & Argument quality & 2.45 & 1 & 2.45 & 2.39 \\
& Humor & 0.28 & 1 & 0.28 & 0.28 \\
& Regulatory focus & 1.32 & 1 & 1.32 & 1.29 \\
& Argument quality x Humor & 5.84 & 1 & 5.84 & $5.70^{*}$ \\
& Argument quality x Regulatory & & & & \\
& focus & 0.00 & 1 & 0.00 & 0.00 \\
& Humor x Regulatory focus & 3.71 & 1 & 3.71 & 3.62 \\
& Argument quality x Humor x & & & & \\
& Regulatory focus & 7.83 & 1 & 7.83 & $7.65^{*}$ \\
& Error & 182.19 & 178 & 1.02 & \\
\cline { 2 - 6 } & & & & &
\end{tabular}

Note: $\mathrm{N}=186, \mathrm{R}^{2}=.11$, adj. $\mathrm{R}^{2}=.07,{ }^{*} \mathrm{p}<.05$

Hypothesis $4 \mathrm{~b}$ is parallel to Hypothesis $4 \mathrm{a}$, but with investment likelihood as the dependent variable. Hypothesis $4 \mathrm{~b}$ suggested that investors exposed to humor that 
accompanied strong (weak) arguments would have a higher (lower) investment likelihood, especially when they had a promotion focus. Hypothesis $4 \mathrm{~b}$ was supported, and the means with 95\% CI bars are presented in Figure 2. ANOVA indicated that the 3way interaction was significant $\left(\eta_{p}^{2}=.04\right.$, power $\left.=.79\right)($ see Table 4$)$. A visual inspection of the pattern of means in Figure 2 suggests a very similar pattern for the investment likelihood dependent variable as was obtained for the pitch perceptions dependent variable. Specifically, the interaction between argument quality and humor is only present in the promotion-focused condition, and not the prevention-focused condition. Pairwise comparisons of means confirmed this basic pattern. Specifically, for promotionfocused participants, there was a statistically significant mean difference between the strong and weak argument mean scores $(d=1.00,95 \% \mathrm{CI}, .44$ to $1.56 ; p<.05)$ in the humorous condition, although the difference was not significant in the nonhumorous condition. For promotion-focused investors presented with weak arguments, there was also a significant mean difference between the humorous and nonhumorous condition $(d$ $=1.14,95 \% \mathrm{CI},-1.74$ to $-.53, p<.05)$. Such significant mean differences were not observed under the strong argument condition, or for prevention-focused investors in any of the conditions. Similar to H4a, the results suggest that the basic pattern observed in the two-way interaction between humor and argument quality is driven by the fact that those differences were primarily observed in the promotion-focused condition, but not the prevention-focused condition. 
Figure 2

Mean comparisons for investment likelihood
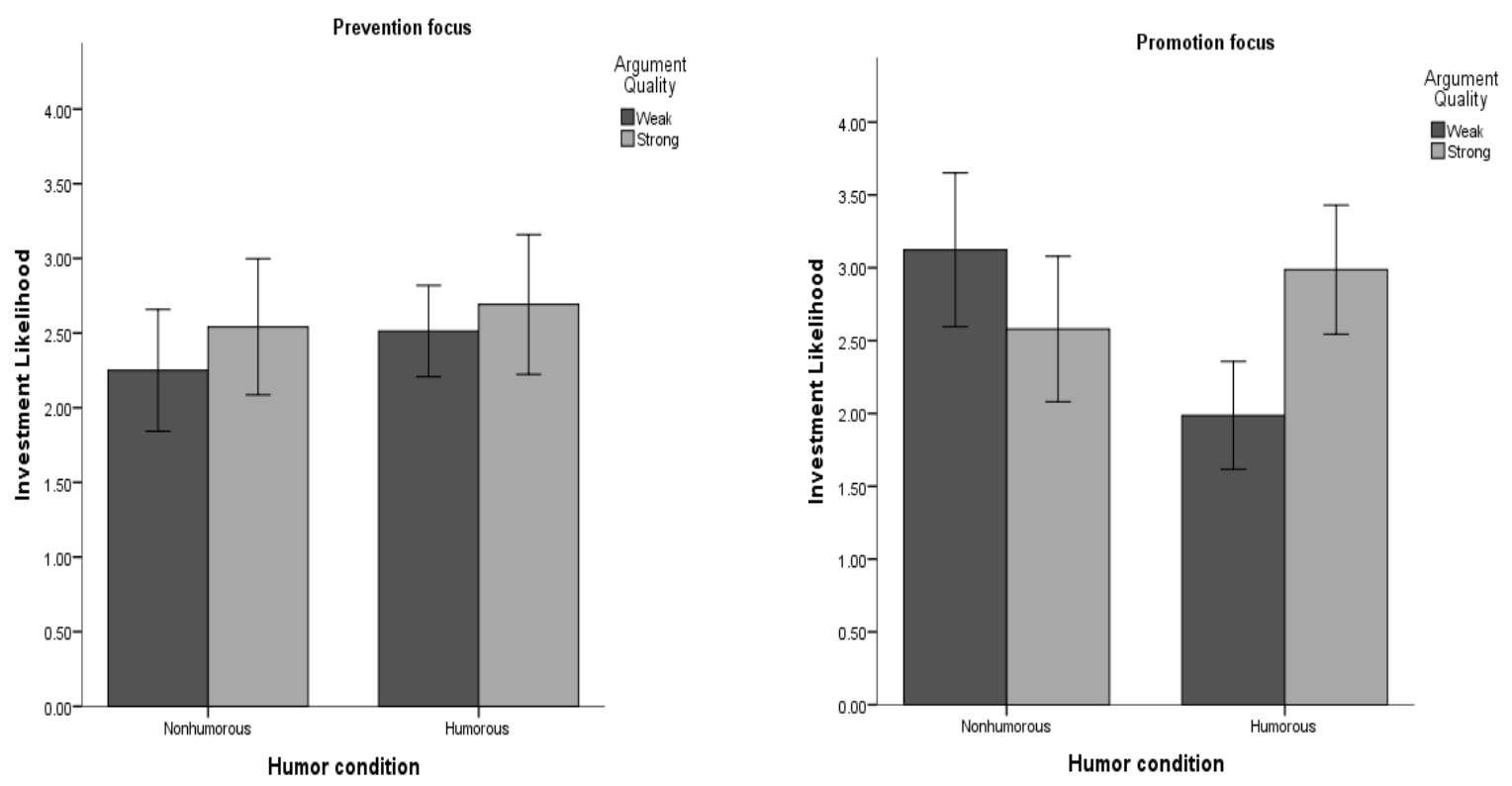


\section{CHAPTER 5: DISCUSSION}

A crucial step in the entrepreneurial process is obtaining funding, and the entrepreneurial pitch is typically a central part of that process. As such, the pitch is a high-stakes activity, and entrepreneurs attempt to shape their pitch in such a way that it not only communicates vital information about the business itself, but captures the attention, imagination, commitment, and cash of investors. Toward that end, entrepreneurs across many different platforms often weave humor into their pitch in order to stand out and ultimately to garner investment.

However, we actually know very little about the conditions under which the use of humor by entrepreneurs is likely to enhance or diminish investors' perceptions of the pitch and their likelihood of investing. Does humor always work, or does it have its limits? In this study, I explored two features of the pitch context to examine this issue: the quality of the arguments supporting the likelihood that the business would ultimately be successful, and the motivational orientation of the investors.

The easiest way to summarize the results of the study is to start with the two-way interaction between humor and argument quality. The results of the two-way interaction suggests that the use of humor in a pitch augments investors' reactions to the pitch and their likelihood of investing in the idea when the humor is presented along with strong, high quality arguments. However, when the arguments are weak, the humor appears to be particularly problematic. This is consistent with the notion that humor might draw attention to the poor arguments, and have a negative effect on investor reactions. However, the two-way interaction pattern was qualified by a three-way interaction with the participant's (investor's) motivational orientation, which was manipulated in this 
study in terms of the participants' regulatory focus (i.e., prevention or promotion). Specifically, the three-way interaction was driven by the fact that only participants who were manipulated to take a promotion focus appeared to be impacted by humor and argument quality in the pitch. In contrast, participants who were manipulated to take a prevention focus appeared to be insensitive to both argument quality and humor.

\section{Theoretical Implications}

The results showed that, compared with promotion-focused participants, prevention-focused participants were not as influenced by whether the pitch they viewed had humorous appeals. The effects of humor were likely lost on prevention-focused investors due their narrow focus of attention that revolves mostly around risk avoidance. On the other hand, promotion-focused investors who are more likely to see the "big picture" when evaluating pitches were much more open to the effects of humor. The results were consistent with the argument that humor influenced promotion-focused investors' cognitive flexibility by increasing their attentiveness to other components of the pitch, such as the quality of arguments, emphasizing the weaknesses or the strengths of the pitch. These results also provide additional support to the literature on regulatory focus in relation to creativity and cognition. There is some evidence in the literature that qualities of increased attentiveness, creativity, cognitive flexibility and open-mindedness are more common among promotion-focused individuals than prevention-focused individuals (Baas, De Dreu, \& Nijstad, 2008). This evidence is also supported by many studies suggesting that while the research on humor has predominantly focused on its affective components, it is also involves an important cognitive component (Wyer \& Collins, 1992) and is highly related to creativity (e.g., O'Quin \& Derks, 1997; Hirt, 
Devers, \& McCrea, 2008). The results of these studies suggest that promotion-focused individuals are much more open to the effects of humor through their tendency to be cognitively more flexible and adept. The results suggest that promotion-focused individuals' cognitive flexibility is enhanced by humor, which helps them attend to a wider array of stimuli and information, thus broadening their perspectives and enabling more creativity (Koestler, 1976). On the other hand, prevention focused investors are not necessarily attentive to humor. This is because they can often have a narrow perspective due their focus on risk and losses rather than gains, which makes them less likely to attend to a broader array of pitch components, and thus less likely to be influenced by the effects of humor.

In addition, contrary to expectations, humor did not influence the pitch evaluation process through its impact on positive affect. Previous studies have found that positive mood states such as enthusiasm, joy and happiness were associated with promotion focus (Frijda, Kuipers, \& Ter Schure, 1989). Other studies have also shown that positive activating moods such as happiness increase cognitive flexibility (De Dreu, Baas, \& Nijstad, 2008; Hirt, Devers, \& McCrea, 2008) and thus broader attentiveness to various stimuli, which are common among promotion-focused individuals. In addition, some theories of humor have argued that humor's impacts come primarily through its impact on positive affect (e.g., Cooper, 2008; Robert \& Wilbanks, 2012). However, the results of this study could not provide additional support for positive affect's influence on promotion-focused investors' perceptions and attitudes toward the pitch. The evidence found for the impact of humor was in the absence of any measured change in affect. 
These results suggest that humor, cognition, and affect are not necessarily linearly arranged, such that humor leads to positive affect, and positive affect leads to broadened cognition. It can even be possible that perceptions of humor might involve cognitive processes, and perhaps increased cognitive flexibility and creativity, without necessarily activating the affective components of the process. For example, a study conducted by Chan, Chou, Chen, Yeh, Lavallee, Liang and Chang (2012) on the comprehensionelaboration theory of humor processing (Wyer and Collins, 1992) looked into different stages of humor processing with the use of functional magnetic resonance imaging technology. They looked at the neurological activity of participants during the process of comprehension of verbal jokes in three conditions (unfunny, nonsensical and funny). They found that humor processing took place in three stages where the initial stages of humor comprehension consisted of incongruity detection and resolution, and the last stage involved the inducement of the feeling of amusement during humor elaboration. The results suggest that the cognition of humor (incongruity detection and resolution) precedes elaboration on the amusing nature of humor, which is what actually ties the neurological processes to the experience of affect. In other words, it is possible that humor can stimulate some of the cognitive components involved in humor appreciation (including cognitive flexibility and creativity) without necessarily stimulating the affective components. Perhaps, for example, in a context such as an entrepreneurial pitch, although people can detect and appreciate humor and its incongruities, they don't have time to truly "elaborate" on humor to elicit an affective reaction.

The results of the study by Chan et al. (2012) along with the previous research linking humor, cognitive processes such as cognitive flexibility and creativity, and affect, 
suggest the possibility of reciprocal relationships between these phenomena, rather than a strictly set of relationships. That is, humor, cognitive flexibility and creativity might form a nexus of relationships, whereby the introduction of any one might engage the others. For example, cognitive flexibility might stimulate creativity and humor, which might influence affect. Similarly, positive affect might stimulate humor and subsequent creativity, or humor might impact cognitive flexibility and positive affect. Indeed, a number of studies found support for each link between these components, providing further support for the nexus as a conceptual framework for how the humor process works. For example, studies have found support for the link between humor and affect in various domains such as leadership (e.g., Gkorezis, Petridou and Xanthiakos, 2015; Pundt and Herrmann, 2015), and advertising (Weinberger and Campbell, 1991); between humor and cognition through creativity (e.g., Brotherton, 1996; Humke \& Schaefer, 1996) and incongruity resolution (Chan et al., 2012; Wyer and Collins, 1992); and between cognition and affect through cognitive flexibility (e.g., Ashby, Isen, \& Turken, 1999; Murray, Sujan, Hirt, \& Sujan, 1990) and mood management (Wegener \& Petty, 1994; Wegener et al., 1995).

The idea of nexus can also be applied to the entrepreneurial pitch contexts to shed more light on how humor might influence the pitch evaluation and investment decisions. Especially in this paper, the nexus might shed more light on why the results did not support a direct relationship between humor and affect. Perhaps this was because participants had limited time for humor elaboration, or the measurement of affect occurred too far after humor itself to be detected (i.e., the positive affect might have been very fleeting), even though affect might have had an indirect impact on pitch evaluation. 
In this case, instead of a dominant humor-affect link, affect might have influenced the process as part of the nexus, by impacting cognitive flexibility and increased scrutiny on the arguments in the pitches. Thus, a fruitful avenue for future research might be to explore whether the links among humor, cognition and affect are indeed reciprocal, and what the directionality of these links looks like during a humor process.

\section{Practical Implications}

The results showed that humor use yielded positive results only when the accompanying arguments were strong. This suggests that humor only works when paired with strong arguments that would support the argument that the business would be a success. Various studies have indeed shown that an entrepreneur's preparedness (i.e., thoughtful, logical presentation with supportive arguments), and not necessarily their display of passion, predicts a successful venture funding decision (Cardon, Sudek, \& Mitteness, 2009; Chen et al., 2009). The results of those studies suggest that even though argument quality and the substance of the presentation are not the only components investors look at, they are likely among the most important components that influence their decision-making. The results of the current study are also in line with these studies on entrepreneurial pitches, such that the effects of humor were maximized in the presence of quality arguments that can imply an entrepreneurs' preparedness and potential venture success. In other words, humor (and other individual pitch components such as enthusiasm and passion) may not be effective by themselves if the foundations of a pitch (i.e., arguments, core information about the venture) are not strong. Therefore, before focusing on how to implement humor during their pitch, entrepreneurs should ensure that they are adequately communicating information about why their business idea is sound 
and likely to succeed. If they feel that they are accomplishing this, then they can perhaps layer on the humor to add more effectiveness to their presentation.

In addition, the results showed that the use of humor was relevant more for promotion-focused investors than prevention-focused investors. From a practitioner standpoint, this suggests that entrepreneurs need to be aware of the profile of investors for whom they are pitching. Are they more interested in the process and experience of providing funds, or are they in it only to maximize return-on-investment? If entrepreneurs can have an understanding of investor profiles before they get to the actual pitch stage, they might have a better chance of gauging the potential for humor use for their success. In this case, depending on their arguments, they are likely to be more successful with their use of humor when pitching to a group of investors that are relatively more promotion-focused. Studies indeed show that crowdfunders display these characteristics of a promotion focus, as their motivations appear to go beyond economic factors (Ordanini et al., 2011). Crowdfunding platforms such as Indiegogo and Kickstarter provide some of the context where humor use might be appreciated more, as opposed to other investment options involving venture capitalists who may represent the most formal of the funding options.

It is also important to note that there may be investors that show characteristics of both a prevention and promotion focus. Indeed, studies have shown that during the investment process, angel investors rely on their expertise and entrepreneurial experience as well as their instincts, and tend to invest opportunistically (Van Osnabrugge \& Robinson, 2000). They also tend to maintain their involvement with the companies in which they invest, with motivations that often go beyond return-on-investment such as 
keeping up with the developments in the field, engaging in mentoring, and making use of the entrepreneur's networks (Van Osnabrugge \& Robinson, 2000). Having an audience that shows both characteristics of the regulatory foci can indeed be an interesting avenue for experimentation for entrepreneurs, as well as researchers, because it might be possible for entrepreneurs to engage in actions that further bring out the promotion focus in their audience, while minimizing the prevention focus. Even though some investors might have strong predilections toward a prevention or a promotion focus, entrepreneurs might be able to rely on various linguistic and rhetorical tools to divert audience attention to a bigger-picture contribution such as making a difference to society through their investment into the venture, which might influence pitch outcomes.

\section{Limitations and Future Research}

This study has a number of limitations, some of which present opportunities for future research. First, the generalizability of the study may be limited because 155 out of 186 respondents reported that they had no prior investment experience. Therefore, people

who are much more closely engaged with investment might behave somewhat differently, and perhaps focus on different aspects of entrepreneurial pitches. Also, the sample was composed of U.S. students attending a single university in the Midwest, and the data is not necessarily representative of investment behaviors at the national level. It is also likely that there are other geographic factors that might influence investment behavior. For instance, investors might be more willing to support entrepreneurial businesses in geographic locations known for increasing entrepreneurial activities or resources for entrepreneurs. In a similar vein, cross-cultural differences can also play a part in humor 
appreciation in pitch contexts. For example, in different countries, cultural norms can make humor either more or less viable as a pitch strategy. In some countries, humor might almost never work as part of a pitch if it is deemed inappropriate in accordance with cultural norms, regardless of argument quality.

Second, it is important to note that the lack of support for humor's effect through positive affect might be due the methodology utilizing a video presentation, rather than a richer interaction such as a face-to-face pitch. It is possible that humor didn't have as much of an affective punch in the video presentation format that richer pitch contexts might have had. In addition, although a video pitch might be a reasonable approximation of entrepreneurial channels such as crowdfunding, it might not be a sufficient analog to other channels such as angel investing or venture capital. Future research might explore those richer contexts to further evaluate the possibility that humor might have effects via an affective channel in different settings other than a video platform such as crowdfunding. It is also possible that an effect of positive affect was not detected in this study, because the measurement of affect used was not clearly tied to the humor in the pitch itself. For example, if affect was measured with statements such as "Watching the pitch/ The humor in the pitch made me feel energetic and positive," instead of the more general statement "I'm feeling very energetic and positive," it would be easier to detect an effect for positive affect. Therefore, future research might benefit from more direct statements as survey items to measure affect in pitch contexts.

Third, in this study, humorous appeals were used based on the results of a pilot study where respondents evaluated various video clips and photos based on their level of humor. However, this study did not look at different types of humor and their differential 
effects on investors. The specific ways entrepreneurs use humor in a pitch might have differential effects on the investors. For example, an entrepreneur may have a humorous personality and naturally incorporate humor in the way he or she communicates the message. This type of humor appeal might have a completely different impact on an investor's perception of the entrepreneur and the pitch, compared to that resulting from canned jokes, or even humorous non-verbal cues, such as facial expressions. Future research may investigate the role of different types of humor and how they can influence investors and pitch outcomes. Researchers can also examine real pitches from either crowdfunding sites or videos, or real pitches that take place face-to-face with angel investors to investigate the impact of different types of humor in different contexts.

Fourth, even though the manipulation check for the humor condition showed a significant difference between the nonhumorous and humorous conditions based on the participants' perceptions of humor use in the pitches, the variance observed for the overall level of humor perceived in the humor condition was high. This is likely due to the fact that people have different perceptions about humor, and their appreciation for what is funny can differ vastly from one another. Therefore, in this study the participants' perceptions of humor (i.e., to what extent they found the humorous content funny) showed high levels of variability for the humor content used in the pitches.

Fifth, the frequency of humorous appeals and where humor is used in a pitch might also influence the way humor is perceived. Humor used in relevant parts of a pitch (i.e., when it makes most sense in relation to the flow of the pitch) and humor related to the content /pitch idea can have a more positive impact on how the overall pitch is perceived, whereas humor that is used too frequently and irrelevant to the business idea 
can lead to negative overall impressions of the pitch. In this study, the humorous appeals used were relevant to the business idea and there were 5 points throughout the humorous version of the pitch where humor was used. Therefore the results may not be representative of pitches where humor relatedness and frequency are different from the ones in this study. Researchers can thus look into how variances in humor frequency and humor relatedness might influence various pitch outcomes.

Lastly, there is some evidence in the literature that the entrepreneur's gender might influence pitch outcomes. In their study of venture investment, Brooks, Huang, Kearney and Murray (2014) found that investors preferred pitches presented by male entrepreneurs compared with pitches made by female entrepreneurs. The pitches were found to be even more persuasive if the male entrepreneurs were physically attractive, whereas physical attractiveness did not matter among female entrepreneurs. In this study, the actress hired to perform as an entrepreneur was a female, and therefore the results might have been different if the actor was a male. Researchers can look into the role an entrepreneur's gender might play in pitch evaluation outcomes when humor is involved.

\section{Conclusions}

This study helped introduce humor to the entrepreneurship literature as a potential mechanism that can have serious consequences for investors' reactions to a pitch and various pitch outcomes. The study aims to enhance our understanding of how pitches are perceived under different conditions, and given the widespread use of humorous appeals in entrepreneurial pitches, to help us find new ways to look at the questions "What makes a good pitch?" and "How do people use humor?" 
The results of the study showed that humor, in conjunction with investor motivation and argument quality, have consequences for pitch evaluations. Specifically, when investors keep an open mind toward investment and pitches in general (e.g., promotion-focus), they are much more likely to be influenced by the effects of humor, compared to prevention-focused investors. However, such an influence also enhances scrutiny on other components of the pitch, making it more likely for investors to notice or focus on components that raise red flags, if there are any, leading to an unsuccessful pitch outcome. Thus, the results suggest that, with the increasing importance of an entrepreneurial economy and "pitches" as one of the most influential tools that allow entrepreneurs to connect with alternative funding sources, entrepreneurs wanting to "add flavor" to their pitches to make them more appealing need to proceed with caution. 


\section{REFERENCES}

Apter, M. J. (1982). Fawlty Towers: A reversal theory analysis of a popular television comedy series. The Journal of Popular Culture, 16, 128-138.

Ashby, F. G., Isen, A. M., \& Turken, A. U. (1999). A neuropsychological theory of positive affect and its influence on cognition. Psychological Review, 106, 529550.

Baas, M., De Dreu, C. K. W., \& Nijstad, B. A. (2008). A meta-analysis of 25 years of mood-creativity research: Hedonic tone, activation, or regulatory focus? Psychological Bulletin, 134, 779-806.

Brockner, J., \& Higgins, E. T. (2001). Regulatory focus theory: Implications for the study of emotions at work. Organizational Behavior and Human Decision Processes, 86, 35-66.

Brockner, J., Higgins, E. T., \& Low, M. B. (2004). Regulatory focus theory and the entrepreneurial process. Journal of Business Venturing, 19, 203-220.

Brooks, A. W., Huang, L., Kearney, S. W., \& Murray, F. E. (2014). Investors prefer entrepreneurial ventures pitched by attractive men. Proceedings of the National Academy of Sciences, 111, 4427-4431.

Brotherton, P. (1996). Tools from the HR Desk: Candid Feedback Spurs Changes in Culture. HR Magazine, 41, 47. 
Cardon, M. S., Sudek, R., \& Mitteness, C. (2009). The impact of perceived entrepreneurial passion on angel investing. Frontiers of Entrepreneurship Research, 29, 1-15.

Chaiken, S. (1980). Heuristic versus systematic information processing and the use of source versus message cues in persuasion. Journal of Personality and Social Psychology, 39, 752-766.

Chan, Y. C., Chou, T. L., Chen, H. C., Yeh, Y. C., Lavallee, J. P., Liang, K. C., \& Chang, K. E. (2013). Towards a neural circuit model of verbal humor processing: An fMRI study of the neural substrates of incongruity detection and resolution. Neuroimage, 66, 169-176.

Chapman, A. J., \& Foot, H. C. (1977). It's a funny thing, humour: Pergamon.

Chen, X. P., Yao, X., \& Kotha, S. (2009). Entrepreneur passion and preparedness in business plan presentations: A persuasion analysis of venture capitalists' funding decisions. Academy of Management Journal, 52, 199-214.

Cooper, C. (2008). Elucidating the bonds of workplace humor: A relational process model. Human Relations, 61, 1087-1115.

Crowe, E., \& Higgins, E. T. (1997). Regulatory focus and strategic inclinations: Promotion and prevention in decision-making. Organizational Behavior and Human Decision Processes, 69, 117-132.

De Dreu, C. K., Baas, M., \& Nijstad, B. A. (2008). Hedonic tone and activation level in the mood-creativity link: toward a dual pathway to creativity model. Journal of personality and social psychology, 94, 739-756. 
Dubitzky, W., Kötter, T., Schmidt, O., \& Berthold, M. R. (2012). Towards creative information exploration based on Koestler's concept of bisociation. Berlin: Springer.

Eliav, E., Miron-Spektor, E., \& Bear, J. B. (2017). Humor and Creativity. The Psychology of Humor at Work: A Psychological Perspective. New York: Routledge.

Feloni, R. (2015). Why “Shark Tank” investor Robert Herjavec says this entrepreneur might be the best in the show's history. Business Insider. Retrieved from http://www.businessinsider.com/robert-herjavec-emazinglights-best-on-sharktank-2015-3 (accessed on July 4, 2016)

Förster, J., Higgins, E. T., \& Bianco, A. T. (2003). Speed/accuracy decisions in task performance: Built-in trade-off or separate strategic concerns? Organizational Behavior and Human Decision Processes, 90, 148-164.

Frijda, N. H., Kuipers, P., \& Ter Schure, E. (1989). Relations among emotion, appraisal, and emotional action readiness. Journal of Personality and Social Psychology, 57, 212.

Gamache, D. L., McNamara, G., Mannor, M. J. \& Johnson, R. E. (2015). Motivated to acquire? The impact of CEO regulatory focus on firm acquisitions. Academy of Management Journal, 58, 1261-1282.

Gervais, M., \& Wilson, D. S. (2005). The evolution and functions of laughter and humor: A synthetic approach. The Quarterly Review of Biology, 80, 395-430. 
Gkorezis, P., Petridou, E., \& Xanthiakos, P. (2014). Leader positive humor and organizational cynicism: LMX as a mediator. Leadership \& Organization Development Journal, 35, 305-315.

Gürhan-Canli, Z., \& Batra, R. (2004). When corporate image affects product evaluations: The moderating role of perceived risk. Journal of Marketing Research, 41, 197205.

Halvorson, H. G., \& Higgins, E. T. (2013). Do you play to win--or to not lose?. Harvard business review, 91, 117-20.

Higgins, E. T. (1997). Beyond pleasure and pain. American Psychologist, 52, 1280-1300.

Higgins, E. T. (1998). The aboutness principle: A pervasive influence on human inference. Social Cognition, 16, 173-198.

Higgins, E. T. (2000). Making a good decision: value from fit. American Psychologist, 55, 1217-1230.

Hirt, E. R., Devers, E. E. \& McCrea, S. M. (2008). I want to be creative: Exploring the role of hedonic contingency theory in the positive mood-cognitive flexibility link. Journal of personality and social psychology, 94, 214-230.

Houston, D. M., McKee, K. J., Carroll, L., \& Marsh, H. (1998). Using humour to promote psychological wellbeing in residential homes for older people. Aging \& Mental Health, 2, 328-332.

Humke, C., \& Schaefer, C. E. (1996). Sense of humor and creativity. Perceptual and Motor Skills, 82, 544-546. 
Koestler, A. (1964). The act of creation. New York: Macmillan.

Kruglanski, A. W., \& Thompson, E. P. (1999). Persuasion by a single route: A view from the unimodel. Psychological Inquiry, 10, 83-109.

Kudrowitz, B. M. (2010). Haha and aha!: Creativity, idea generation, improvisational humor, and product design (Doctoral dissertation, Massachusetts Institute of Technology).

Lynch, O. H. (2002). Humorous communication: Finding a place for humor in communication research. Communication Theory, 12, 423-445.

Mackie, D. M., \& Worth, L. T. (1989). Processing deficits and the mediation of positive affect in persuasion. Journal of Personality and Social Psychology, 57, 27-40.

Mannell, R. C., \& McMahon, L. (1982). Humor as play: Its relationship to psychological well-being during the course of a day. Leisure Sciences, 5, 143-155.

Martin, R. A., Kuiper, N. A., Olinger, L. J., \& Dance, K. A. (1993). Humor, coping with stress, self-concept, and psychological well-being. Humor, 6, 89-89.

Martin, R. A. (2007). The psychology of humor: An integrative approach. Amsterdam, Netherlands: Elsevier.

Mobbs, D., Hagan, C. C., Azim, E., Menon, V., \& Reiss, A. L. (2005). Personality predicts activity in reward and emotional regions associated with humor. Proceedings of the National Academy of Sciences, 102, 16502-16506. 
Moons, W. G., Mackie, D. M., \& Garcia-Marques, T. (2009). The impact of repetitioninduced familiarity on agreement with weak and strong arguments. Journal of Personality and Social Psychology, 96, 32-44.

Moran, C. C. (1996). Short-term mood change, perceived funniness, and the effect of humor stimuli. Behavioral Medicine, 22, 32-38.

Murray, N., Sujan, H., Hirt, E. R., \& Sujan, M. (1990). The influence of mood on categorization: A cognitive flexibility interpretation. Journal of Personality and Social Psychology, 59, 411-425.

Neubert, M. J., Kacmar, K. M., Carlson, D. S., Chonko, L. B., \& Roberts, J. A. (2008). Regulatory focus as a mediator of the influence of initiating structure and servant leadership on employee behavior. Journal of Applied Psychology, 93, 1220-1233.

Newman, M. G., \& Stone, A. A. (1996). Does humor moderate the effects of experimentally-induced stress? Annals of Behavioral Medicine, 18, 101-109.

O'Quin, K., \& Derks, P. (1997). Humor and creativity: A review of the empirical literature. Creativity Research Handbook, 1, 223-252.

Ordanini, A., Miceli, L., Pizzetti, M., \& Parasuraman, A. (2011). Crowd-funding: Transforming customers into investors through innovative service platforms. Journal of Service Management, 22, 443-470.

Pan, W., Sun, L. Y., \& Chow, I. H. S. (2012). Leader-member exchange and employee creativity: Test of a multilevel moderated mediation model. Human Performance, 25, 432-451. 
Petty, R. E., \& Cacioppo, J. T. (1986). The elaboration likelihood model of persuasion. In L. Berkowitz (Ed.), Advances in experimental social psychology (pp. 123-205). New York: Academic.

Pundt, A., \& Herrmann, F. (2015). Affiliative and aggressive humour in leadership and their relationship to leader-member exchange. Journal of Occupational and Organizational Psychology, 88, 108-125.

Riquelme, H., \& Watson, J. (2002). Do venture capitalists' implicit theories on new business success/failure have empirical validity? International Small Business Journal, 20, 395-420.

Robert, C., \& Wilbanks, J. E. (2012). The wheel model of humor: Humor events and affect in organizations. Human Relations, 65, 1071-1099.

Robert, C.. \& Seyrek, S. U. (2017) Paradoxes in Workplace Humor Research: Theory, culture, and the messy work of moving forward. The Psychology of Humor at Work: A Psychological Perspective. New York: Routledge.

Shiota, M. N., Campos, B., Keltner, D., \& Hertenstein, M. J. (2004). Positive emotion and the regulation of interpersonal relationships. In P. Philippot \& R. S. Feldman (Eds.), The regulation of emotion (pp. 127-155). Mahwah, NJ: Lawrence Erlbaum Associates.

Smith, E. E., \& Goodchilds, J. D. (1963). The wit in large and small established groups. Psychological Reports, 13, 273-274. 
Szabo, A. (2003). The acute effects of humor and exercise on mood and anxiety. Journal of Leisure Research, 35, 152-162.

Van Osnabrugge, M. \& Robinson, R. J. (2000). Angel investing: Matching start-up funds with start-up companies: The guide for entrepreneurs, individual investors, and venture capitalist. San Francisco: Jossey-Bass.

Wegener, D. T., \& Petty, R. E. (1994). Mood management across affective states: The hedonic contingency hypothesis. Journal of Personality and Social Psychology, 66, 1034-1048.

Wegener, D. T., Petty, R. E., \& Smith, S. M. (1995). Positive mood can increase or decrease message scrutiny: The hedonic contingency view of mood and message processing. Journal of Personality and Social Psychology, 69, 5-15.

Weinberger, M. G., \& Campbell, L. (1991). The use and impact of humor in radio advertising. Journal of Advertising Research, 30, 44-52.

Weisfeld, G. E. (1993). The adaptive value of humor and laughter. Ethology and Sociobiology, 14, 141-169.

White, S., \& Winzelberg, A. (1992). Laughter and stress. Humor: International Journal of Humor Research, 5, 343-355.

Wood, R. E., Beckmann, N., \& Rossiter, J. R. (2011). Management humor: Asset or liability? Organizational Psychology Review, 1, 316-338.

Wyer, R. S., \& Collins, J. E. (1992). A theory of humor elicitation. Psychological Review, 99, 663-688. 
Zhang, Y. (1996). The effect of humor in advertising: An individual-difference perspective. Psychology \& Marketing, 13, 531-545.

Ziv, A. (1988). Teaching and learning with humor: Experiment and replication. The Journal of Experimental Education, 57, 4-15. 


\section{APPENDIX: SURVEY}

\section{Consent Form}

Thank you for your interest in participating in this research. The goal of this research is to understand how people make investment decisions. For your participation in all studies, you will receive 3 extra credits in your class. As an alternative to the research participation (you do not wish to participate in the research described above, but would like to complete an alternative assignment instead) you may hand-write a 2-page essay on the theme: "Leadership, Integrity, and Use of a Digital Device: How I Can Improve My Intellectual Capacity and Soft Skills by Turning Off My Digital Device, Tuning into My Professor, and Dropping In My Notes of Reflection”. The essay must be completed using a pen or pencil and a blue book and must contain no fewer than 200 words per page.

To complete the survey, you must be at least 18 years old.

Participating in this research will take approximately 15-25 minutes. You will be given a set of questionnaires then you will be asked to view a video of an investment opportunity and complete another set of questionnaires. You are asked to complete each section before moving onto the next section. The results of this project might be published, but all information collected will be kept strictly confidential. Throughout the study, we will not ask for your name or for other identifying information (e.g., phone or social security numbers) that could link your responses to your name. At the end of the survey, you will be asked to enter the code you were assigned before your participation, which will be used to give you the extra credit. We also want you to be aware that your participation in this study is entirely voluntary and you may withdraw from the study at any time for any reason. If you start the study but withdraw, you will receive partial extra-credit. Although it is not possible to identify all potential risks in this or any other study, no clearly risky procedures have been included in this study, and we do not believe participation in this study involves risks greater than those ordinarily encountered in daily life. Thank you for considering helping in this research.

Sincerely, Scott Seyrek, PhD Candidate, 573-999-6115

(Chris Robert, Faculty Supervisor 573-882-3819)

Department of Management

University of Missouri-Columbia

Please click 'next / >>' to agree that you are at least 18 years old, and that you understand and give your consent to participate. Your consent does not constitute a waiver of any legal rights. If you have questions concerning human subject research please call the Institutional Review Board at 573-882-9585. 
Please wear the earbuds provided to you now, by plugging them into the port located on the front side of the PC ( $\mathrm{PC}$ is located behind the screens), before moving onto the next page. Be sure to press and hold the "increase volume" button located on the top side of your keyboard to maximize volume of the PC. If you notice the volume is low, make sure the volume on both the PC and the Youtube Video is maximized. If you notice the buds don't work properly after you start the video, raise your hand and let the administrator help you by providing a new pair of earbuds. In that case, please restart the video.

(Participants randomly received one of the following two statements)

In the next section, we want you to imagine that you are an investor who is interested in investing in various entrepreneurial ventures. You have recently been asked to evaluate a pitch and make an investment decision. As you evaluate the pitch and respond to questions, we want you to approach the pitch with the following mindset: your goal is to increase your financial security by avoiding risk as much as possible. You do not want to risk your funds for low expected return on investment. You should be very careful to avoid making a decision that would expose yourself to potential financial losses. Therefore, be vigilant about anything that signals risk and a lack of potential in the venture, and evaluate the pitch accordingly.

In the next section, we want you to imagine that you are an investor who is interested in investing in various entrepreneurial ventures. You have recently been asked to evaluate a pitch and make an investment decision. As you evaluate the pitch and respond to questions, we want you to approach the pitch with the following mindset: you are comfortable taking risks to maximize potential success. You like to take chances if you believe you identify with the ideas and see potential growth. Your priorities are impacted by your desire to help other entrepreneurs grow and experiment with venture ideas for personal development. Therefore, be open-minded and flexible. Focus on how the pitch makes you feel and how you identify with it, and evaluate the pitch accordingly.

(Participants randomly received one of the four videos for viewing)

The pitch you are about to view was recorded on a low budget. Because of this, you may find that the video and audio quality is low (e.g., background, setting, changes in audio quality). To the extent possible, please try to ignore these factors, and keep them from influencing your 
evaluations of the pitch. Please be sure to watch the pitch until the very end and pay attention to the code at the end of the video before moving onto the next section.

Enter the letter (in capitals) that appears at the end of the video on the next page

Describe the extent to which you agree with the following statements about how you feel right now, that is, at the present moment.

\begin{tabular}{|c|c|c|c|c|c|}
\hline & $\begin{array}{l}\text { Strongly } \\
\text { disagree }\end{array}$ & Disagree & Neutral & Agree & Strongly agree \\
\hline $\begin{array}{l}\text { 1. I feel } \\
\text { interested in } \\
\text { what I am } \\
\text { doing at the } \\
\text { moment }\end{array}$ & $\mathrm{O}$ & $\mathrm{O}$ & $\mathrm{O}$ & $\mathrm{O}$ & $\mathrm{O}$ \\
\hline $\begin{array}{l}\text { 2. I feel pretty } \\
\text { enthusiastic } \\
\text { about my life } \\
\text { right now }\end{array}$ & $\mathrm{O}$ & $\mathrm{O}$ & $\mathrm{O}$ & $\mathrm{O}$ & $\mathrm{O}$ \\
\hline $\begin{array}{l}\text { 3. I'm feeling } \\
\text { inspired }\end{array}$ & $\mathrm{O}$ & $\mathrm{O}$ & O & $\mathrm{O}$ & $\mathrm{O}$ \\
\hline $\begin{array}{l}\text { 4. Right now, } \\
\text { life feels } \\
\text { terrific }\end{array}$ & $\mathrm{O}$ & $\mathrm{O}$ & $\mathrm{O}$ & $\mathrm{O}$ & $\mathrm{O}$ \\
\hline $\begin{array}{l}\text { 5. I'm feeling } \\
\text { energetic and } \\
\text { positive }\end{array}$ & $\mathrm{O}$ & $\mathrm{O}$ & O & O & $\mathrm{O}$ \\
\hline $\begin{array}{l}\text { 6. I feel } \\
\text { determined }\end{array}$ & O & O & O & O & O \\
\hline $\begin{array}{l}\text { 7. I feel very } \\
\text { focused and on } \\
\text { task }\end{array}$ & $\mathrm{O}$ & $\mathrm{O}$ & $\mathrm{O}$ & O & $\mathrm{O}$ \\
\hline $\begin{array}{l}\text { 8. I'm feeling } \\
\text { lively and } \\
\text { cheerful }\end{array}$ & O & 0 & O & $\mathrm{O}$ & O \\
\hline
\end{tabular}


Imagine that you are a potential investor in new ventures who views multiple entrepreneurial pitches. You have budgeted $\$ 1000$ to invest in ventures for the month. Based on your impressions of the pitch you just viewed, please respond to the questions below.

In my view, the business pitch was...

\begin{tabular}{|c|c|c|c|c|c|}
\hline & 1 & 2 & 3 & 4 & 5 \\
\hline Unpleasant:Pleasant & 0 & 0 & 0 & 0 & 0 \\
Unlikable:Likable & 0 & 0 & 0 & 0 & 0 \\
$\begin{array}{c}\text { Irritating:Not } \\
\text { irritating }\end{array}$ & 0 & 0 & 0 & 0 & 0 \\
$\begin{array}{c}\text { Not } \\
\text { interesting:Interesting }\end{array}$ & 0 & 0 & 0 & 0 & 0 \\
\hline
\end{tabular}

What are the chances that you would fund this pitch?

\begin{tabular}{|c|c|c|c|c|c|}
\hline & 1 & 2 & 3 & 4 & 5 \\
\hline Unlikely:Likely & 0 & 0 & 0 & 0 & 0 \\
Improbable:Probable & 0 & 0 & 0 & 0 & 0 \\
Impossible:Possible & 0 & 0 & 0 & 0 & 0 \\
\hline
\end{tabular}

Based on the $\$ 1000$ budget you currently have for multiple pitches, how much would you invest in this venture based on the pitch you have just viewed? (Only enter the number without any decimals; do not include the dollar sign) 
Please indicate your level of agreement with the following statements.

\begin{tabular}{|c|c|c|c|c|c|}
\hline & $\begin{array}{l}\text { Completely } \\
\text { Disagree }\end{array}$ & Disagree & Neutral & Agree & $\begin{array}{c}\text { Completely } \\
\text { Agree }\end{array}$ \\
\hline $\begin{array}{l}\text { 1. I thought the } \\
\text { pitch was amusing }\end{array}$ & O & $\mathrm{O}$ & $\mathrm{O}$ & $\mathrm{O}$ & $\mathrm{O}$ \\
\hline $\begin{array}{l}2 . \text { The } \\
\text { entrepreneur tried } \\
\text { to incorporate } \\
\text { humor into the } \\
\text { pitch }\end{array}$ & $\mathrm{O}$ & O & O & $\mathrm{O}$ & $\mathrm{O}$ \\
\hline $\begin{array}{l}\text { 3. I thought the } \\
\text { pitch was } \\
\text { humorous }\end{array}$ & O & $\mathrm{O}$ & 0 & $\mathrm{O}$ & O \\
\hline $\begin{array}{l}\text { 4. The humor was } \\
\text { integrated } \\
\text { effectively }\end{array}$ & O & $\mathrm{O}$ & $\mathrm{O}$ & 0 & $\mathrm{O}$ \\
\hline $\begin{array}{l}\text { 5. I thought the } \\
\text { pitch was funny }\end{array}$ & O & $\mathrm{O}$ & $\mathrm{O}$ & O & $\mathrm{O}$ \\
\hline $\begin{array}{l}\text { 6. I liked that the } \\
\text { entrepreneur } \\
\text { incorporated } \\
\text { humorous content } \\
\text { into the pitch }\end{array}$ & $\mathrm{O}$ & $\mathrm{O}$ & $\mathrm{O}$ & O & O \\
\hline $\begin{array}{l}\text { 7. I appreciated } \\
\text { the pitch for its } \\
\text { light-hearted } \\
\text { content }\end{array}$ & 0 & $\mathrm{O}$ & 0 & 0 & $\mathrm{O}$ \\
\hline $\begin{array}{l}\text { 8. The pitch had } \\
\text { humorous content } \\
\text { and I enjoyed it }\end{array}$ & O & 0 & O & $\mathrm{O}$ & 0 \\
\hline $\begin{array}{l}\text { 9. The pitch had } \\
\text { funny content that } \\
\text { made me feel } \\
\text { positively about } \\
\text { the pitch. }\end{array}$ & O & $\mathrm{O}$ & $\mathrm{O}$ & O & $\mathrm{O}$ \\
\hline
\end{tabular}


Please evaluate the pitch you have just viewed based on the items below.

"The arguments presented in the pitch were...."

\begin{tabular}{|c|c|c|c|c|c|}
\hline & 1 & 2 & 3 & 4 & 5 \\
\hline Weak:Strong & 0 & 0 & 0 & 0 & 0 \\
Unpersuasive:Persuasive & 0 & 0 & 0 & 0 & 0 \\
$\begin{array}{c}\text { Not } \\
\text { convincing:Convincing }\end{array}$ & 0 & 0 & 0 & 0 & 0 \\
$\begin{array}{c}\text { Bad arguments:Good } \\
\text { arguments }\end{array}$ & 0 & 0 & 0 & 0 & 0 \\
\hline
\end{tabular}

Which of the following statements best reflects your approach when evaluating the pitch you have just viewed? I approached it as if i was:

... careful to avoid risks and avoided exposing myself to potential financial loss.

O ... comfortable taking risks if it meant personal growth or giving entrepreneurs a chance to grow.

Given that you might have paid attention to the pitch as a whole or to specific arguments; how much attention did you give in particular to:

\begin{tabular}{|l|c|c|c|c|c|}
\hline & Not at all & Slightly & Moderately & Quite a bit & A lot \\
\hline $\begin{array}{l}\text { 1. Arguments } \\
\begin{array}{l}\text { 2. The pitch as } \\
\text { a whole and } \\
\text { how it made } \\
\text { you feel }\end{array}\end{array}$ & O & O & 0 & 0 & O \\
\hline
\end{tabular}


In the following questions, please read the statements carefully and choose the answer you think is correct based on the information provided during the pitch. Which of the following is correct about the service Grad4U presented in the pitch?

The basic service provided by Grad4U costs about:
○ $\$ 75$
O $\$ 100$
O $\$ 125$
O $\$ 150$

If you are not satisfied with the service and want to withdraw:

Grad4U gives you full refund regardless of when you withdraw

Grad4U refunds you 50\% of the portion of your payment that covers the unused duration

Grad4U refunds you the portion of your payment that covers the unused duration

Grad4U gives you full refund if you could not be matched to a company

Grad4U's service involves

O A formal conversation between you and the Grad4U team only through Skype

An informal conversation between you and the Grad4U team either in-person or through Skype

O An informal conversation between you and the Grad4U team only in-person

A formal conversation between you and the Grad4U team either in-person or through Skype.

Which of the following is NOT among Grad4U's plans in using your funds:

Hire new team members/developers to work on the web platform

O Partner up with companies to outsource some of their tasks

Develop a user-friendly interface

Provide easy access to all of their services 
Please rate the following statements regarding the pitch.

\begin{tabular}{|l|c|c|c|c|c|}
\hline $\begin{array}{l}\text { 1. Overall production } \\
\text { quality of the video }\end{array}$ & Very low & Low & Medium & High & Very high \\
$\begin{array}{l}\text { 2. Fluency and clarity } \\
\text { of the speaker }\end{array}$ & 0 & 0 & 0 & 0 & 0 \\
$\begin{array}{l}\text { 3. Confidence of the } \\
\text { speaker }\end{array}$ & 0 & 0 & 0 & 0 & 0 \\
$\begin{array}{l}\text { 4.Likeability of the } \\
\text { speaker }\end{array}$ & 0 & 0 & 0 & 0 & 0 \\
$\begin{array}{l}\text { 5. Professionalism of } \\
\text { the speaker }\end{array}$ & O & 0 & 0 & 0 & 0 \\
\hline
\end{tabular}

How many times have you invested in an entrepreneurial venture prior to this experiment?
○ 0
O $1-3$ times
O More than 3

Your gender:

O Male

O Female

Your age: [...]

Year in school (enter numerical): [ ...

Current level of education in progress

O Bachelor's Degree

O Master's Degree

Doctorate Degree

O Other 
Major

O Business (e.g., Management, Accounting, Entrepreneurship, Finance, etc...)

O Non-Business (e.g., Law, Healthcare, Journalism, etc...)

GPA: $[\ldots]$

How would you rate your ability to understand English when spoken to you?

V Very well

O Well

O Not well 


\section{VITA}

Scott U. Seyrek was born and raised in Istanbul, Turkey. He received his undergraduate degree in English Language and Literature from Bogazici University. $\mathrm{He}$ also earned an MBA degree at Bogazici University. During that time, he started working as an instructor at a private language school, where he taught general English to adults for 2 years. Later, he attended the University of Missouri where he successfully completed his $\mathrm{PhD}$ in Management in July 2017.

Scott will be an Assistant Professor of Management at Sage College of Albany, beginning Fall 2017. 